\title{
Synthetic and Jet Fuels Pyrolysis for Cooling and Combustion Applications.
}

\author{
N Gascoin ${ }^{1}$, G Abraham and P Gillard \\ PRISME, IUT Bourges, 63, avenue de Lattre de Tassigny - 18000 Bourges, France
}

\begin{abstract}
Large heat load are encountered in hypersonic flight applications due to the high vehicle speed (over Mach 5, i.e. $5000 \mathrm{~km} . \mathrm{h}-1$ ) and to the combustion heat release. If passive and ablative protections are a way to ensure the thermal management, the regenerative cooling is probably the most efficient one to enable the structures withstanding (notably for reusable structures). The present study is a part of COMPARER project (COntrol and Measure of PArameters in a REacting stReam) which aims at investigating the highly coupled phenomenon (heat and mass transfers, pyrolysis, combustion) in a cooling channel surrounding a SCRamjet combustion chamber and at proposing some parameters to enable the control of such a complex technology. In this paper, we present the comparative numerical pyrolysis study of some selected synthetic and jet fuels (heptane, decane, dodecane, kerosene surrogate). The fluid pyrolysis has been studied experimentally and the results of RESPIRE numerical simulation under lab and in-flight conditions are given with validation to provide a deep understanding of phenomenon. The impact of the density, of the critical parameters, of the viscosity and of the chemistry is investigated to analyze their effect on the cooling efficiency of the engine. That also enables to estimate which properties the best cooling fuel should have. Furthermore, a combustion study is conducted because the cooling fuel is the one that ensure the thrust. The RESPIRE code enables to conduct both coupled pyrolysis and combustion studies. A first approach of the dynamic regeneratively cooled SCRamjet is provided to get a large vision of the fuel nature impact on the system.
\end{abstract}

Keywords: Fuel pyrolysis; Supercritical state; Detailed mechanism; Numerical simulation; GC/MS; FTIR.

\section{Introduction}

Hypersonic flight (over Mach 6) is expected to be achieved in the coming years by means of supersonic combustion ramjet (SCRamjet) [1]. For such high velocity, the total temperature of external air, considering the flow velocity, can reach $1650 \mathrm{~K}$ at Mach 6 and $4950 \mathrm{~K}$ at Mach 12. This produces a dramatic heating, which is added to the heat flux coming from the combustion heat release. Even composite materials could not withstand such large heat load. Furthermore, the time allocated for the combustion in SCRamjet mode is about $1 \mathrm{~ms}$ [2]. The thermal management of the overall vehicle and more specifically of the combustion chamber (CC) is thus an important focus for the aerospace research [3]. In this framework, the COMPARER program (COntrol and Measure of PArameters in a REacting stReam) has been settled by MBDA-France and by the University of Orléans (France). It consists in studying the existing cooling strategy and in testing suitable measurement methods for the regulation. Indeed, an integrated solution using the fuel is considered. Hydrogen could be used as cooling fluid but due to safety and ease of storage reasons, hydrocarbons are often preferred for flight Mach number under 8 . The hydrocarbon fuel is injected in a channel equipped with pin fin. It surrounds the engine. In more efficient systems, the ceramic matrices composite are used [4]. A counter-flow heat exchanger is thus available towards the burned gases. When heated above $800 \mathrm{~K}$, the fuel is pyrolysed and thanks to its endothermic behavior, it increases the active cooling of the hot walls. This pyrolysis produces lighter hydrocarbon species with shorter ignition delays than the initial fuel. This is particularly interesting for the combustion because of short residence time in the combustion chamber. It is important to note that the expected high pressure in the cooling loop ( $>3 \mathrm{MPa}$ ) causes the fluid to become

\footnotetext{
${ }^{1}$ Corresponding author. Tel.: +33 248238 473; Fax: +33 248238471 .

E-mail address: Nicolas.Gascoin@ @ourges.univ-orleans.fr (N. Gascoin).
} 
supercritical in the channel. Furthermore, the wall of the cooling channel in contact with the CC can be porous; creating a thin film cooling that contributes to protect it from the hot gases.

The complete system is a coupled process. The engine thrust depends on the chemical fuel composition injected in the combustion chamber but this composition is linked to thermal heat flux applied on the cooling channel depending on the air/decomposed hydrocarbon combustion. The latest is related to the combustion. Because of this interaction between combustion and pyrolysis, it is useful during the flight to have information about the fuel composition.

The code, called RESPIRE (a French acronym for SCRamjet Cooling with Endothermic Fuel, Transient Reactor Programming), is a one dimensional program able to simulate the hypersonic vehicle cooling as well an academic chemical reactor heated by a furnace. It considers an existing detailed pyrolysis mechanism (1185 reactions, 153 species) [5] for the n-dodecane but it could treat other fluids with appropriate pyrolysis mechanism or with data tables giving the fluid properties [6]. The n-dodecane is used because of its purity and because it is representative of aeronautic kerosene. It is also used experimentally.

We have shown in previous works that the chemical composition of pyrolysed mixture is complex; more than hundred of compounds are produced [7]. A wide spectrum of pyrolysis conditions is covered in studies of the open literature (fluid nature, conditions of temperature/pressure/residence time, open/close reactors, dilution ratio, experimental/numerical work,...) [8]-[13]. A deep review is notably available in [14]. Furthermore, the fluid becomes supercritical because of the temperature and the pressure inside the cooling channel. However, to the author's knowledge, there are only very rare papers on the fuel pyrolysis under supercritical state [9],[15] and every study in this field is of great interest to develop the knowledge related to such complex work. In addition, we have experimentally shown in previous work [7][16] a high carbon deposit rate depending on the nature of the channel material [7]. This will be observed numerically in this paper.

The aim of this paper is to present, after validation by experimental data, the pyrolysis of selected fuels (heptane, decane, dodecane, surrogate fuel) in order to understand how physical and chemical effects impact on the cooling efficiency. Then the coupling with combustion in the SCRamjet combustion chamber enables to observe the whole behaviour of each fluid that will differ from one another. As far as we know, this is the first time that such coupled chemically detailed simulation is conducted. This is a first step to estimate fuel ability for cooled SCRamjet engine application.

\section{The RESPIRE code and the validation bench}

RESPIRE enables considering a complete hypersonic vehicle with active cooling (in flight conditions) but also an open chemical reactor in lab conditions (see [2][15] for more details). It allows studying in 0D or 1D approach but under transient conditions, the coupling between the pyrolysis inside the cooling channel and the combustion inside the engine, so as to the thermal consequences on the engine and the thrust of the vehicle. The related equations will be briefly presented in this section. They are written in transient state and the resolving method is a finite differences one. Partial derivative equations are discretized in space with centred explicit scheme and then solved in time with explicit scheme. Several geometric configurations of the cooling channel can be considered (tubular as it is chosen for academic investigation, rectangular, planar or with pin fin as presented in Figure for most of the actual cooling circuits of engines).

\section{Figure 1 should be placed here}

Due to the one dimensional structure of the RESPIRE code, all variables are constant on a cross-section of the fluid or of the material. The fluid is considered to be homogeneous on each slice along the flow. It is treated as an average single phase flow but possibly multi-species. However, the phase or the state of the fluid can be non uniform along the flow. The spatial step is of the order of $5.10^{-3} \mathrm{~m}$ and the time step is automatically adjusted in behalf of the flow velocity to respect the numerical stability conditions. An average temperature is computed in each wall, considering radiative, convective and conductive heat fluxes. The two face's temperatures of each wall are then deduced.

\subsection{Equations}

The velocity of the fluid $V_{f}$ is determined by the momentum equation (Eq. (1)) and its enthalpy $H_{f}$ by the energy equation (Eq. (2)). The index (ef, if, cw, hw, CC and f) are understandable on Figure 1. The frictions are computed with Eq. (3) and they are based on semi-empirical correlations. The equations are given without the permeation term even if effusion through the walls can be investigated thanks to the Darcy's and Forchheimer's laws. 


$$
\begin{gathered}
\frac{\partial\left(\rho_{f} \cdot V_{f}\right)}{\partial t}+\frac{\partial\left(\rho_{f} \cdot V_{f}^{2}\right)}{\partial x}=-\frac{\partial P_{s f}}{\partial x}+\frac{\partial \tau}{\partial x} \\
\frac{\partial\left(\rho_{f} \cdot H_{f}\right)}{\partial t}+\frac{\partial\left(\rho_{f} \cdot V_{f} \cdot H_{f}\right)}{\partial x}= \\
+\frac{1}{h_{c a n}} h_{c w-f}\left(T_{c w}-T_{s f}\right) \frac{\partial P_{s f}}{\partial t}+\frac{\partial}{\partial x}\left(-j_{q}+V_{f} \cdot \tau\right)+\rho \cdot \sum_{s p e c i e s} h_{i, 0} \cdot w_{i} \\
\frac{\partial \tau}{h_{c a n}} h_{i f-f}\left(T_{i f}-T_{f}\right) \\
=-\frac{C_{f}}{2} \times \rho \cdot V_{f}^{2} \times \frac{4}{D_{H}}
\end{gathered}
$$

with $\rho_{f}$ the fluid density, $t$ the time, $x$ the abscissa, $P_{s f}$ the static pressure, $D_{H}$ the hydraulic diameter, $C_{f}$ the friction coefficient, $\beta_{c}=1 / \rho \times \partial \rho /\left.\partial T\right|_{P}$ the thermal expansion coefficient, $j_{q}=-\lambda_{f} \cdot \operatorname{grad}\left(T_{f}\right)$ the thermal conduction term, $\lambda_{f}$ the thermal conductivity, $h_{i, 0}$ the standard enthalpy of species, $h_{c a n}$ the channel height, $h_{c w-f}$ and $h_{i f-f}$ the convective exchange coefficients between the cold wall and internal face respectively with fluid, $T_{c w}$ and $T_{i f}$ the reactor walls temperatures in contact with the fluid.

RESPIRE can handle every fluid nature but the main one is the n-dodecane, for which a very detailed pyrolysis mechanism is available (1185 reactions and 153 species [5]). This model is the minimum one which is able to successfully predict the thermal decomposition. Most of the radical species, which have minimal concentrations in the mixture, play a determining role in the production and consumption of all other species. All compounds must be considered in order to predict their own combustion. Mixtures have never been found to be at thermodynamic state (experimental and numerical work [2]). Chemical composition cannot be given by data tables depending on fluid temperature or pressure because the pyrolysis is fully controlled by the working conditions. This acts to consider detailed chemistry mechanism in relationship to thermal and hydraulic calculations. The net production rates $\left(w_{i}\right)$ of species $i$ are determined using the pyrolysis mechanism and the transport equation (Eq. (4)) is solved for each chemical species inside the cooling channel:

$$
\frac{\partial\left(\rho_{f} \cdot Y_{i}\right)}{\partial t}+\frac{\partial\left(\rho_{f} \cdot V_{f} \cdot Y_{i}\right)}{\partial x}=\rho_{f} w_{i}-\frac{1}{h_{c a n}} \rho_{f y} . V_{f y} . Y_{i}
$$

with $Y_{i}$ the mass fractions of the $i$ species, $\rho_{f y}$ the fluid density through the walls and $V_{f y}$ its velocity.

Dynamic viscosity and thermal conductivity are computed using the method of Guo et al.[17]. The method uses the Peng Robinson Equation of State. CHEMKIN-type polynomials are used to calculate the heat capacity of each species. An equation of state $(P / \rho=Z . r . T)$ is used to determine the density considering the compressibility factor: $Z=Z^{+(0)}+\omega . Z^{+(1)}$ with $\omega=\left(0.2901-Z_{c}\right) / 0.0879$ the Pitzer acentric factor. The Lee-Kesler tables are needed for $Z^{+(0)}, Z^{+(1)}$ and to correct the heat capacity as a function of temperature and pressure. Pressure of fluid is determined by use of Bulk Modulus $\beta=\partial P /(\partial \rho / \rho)$ with $\beta=\rho \cdot c^{2}$ ( $c$ the speed of sound).

A deep validation of thermal, hydraulic and chemical aspects has been conducted under transient and stationary conditions with analytical, numerical and experimental cases. A previous work [7] furnishes a chemical validation under stationary conditions as a validation of the transient thermal and hydraulic behaviour of RESPIRE. Good agreement is found on temperature, compared to the CFD software CFD-ACE (2-D heated tube with tabulated fluid) [6]. Thermal and hydraulic time evolutions are reasonable and quantitative results are adequate for a 1-D model, used as predimensioning tool. Computed chemical compositions are found to be of the same order as validation data (1\% molar fraction discrepancies). Calculations of fluid properties under various conditions, particularly in supercritical state, have been presented and validated in previous work [18]. Considering real pyrolysed mixture properties, and not the one of a perfect pure fluid, can decrease fluid temperature at the cooling channel outlet of about $20 \%$. This justifies its consideration. Transient conduction through channel walls has been investigated using steady state and transient heat flux conditions [19]. Less than a $2 \%$ variation on wall temperature, compared to analytical data, has been found with steady state heat flux. The method used to compute the chemical fluid composition has been validated. Further validations of fluid temperature have been presented in previous work [20]. Finally, the code has been validated experimentally on sub- and supercritical fluid [15] under stationary conditions then under transient ones [21]. The molar fractions are found to be estimated with a discrepancy lower than $2 \%$, which is also the one of the transient experimental method when compared with GC/MS data [22]. 


\subsection{The COMPARER test bench}

To validate the code, a high pressure and high temperature experimental bench (Figure 2) has been set up to enable the study of inert and reactive flows in configurations, which are representative to real in-flight conditions. The bench [15] is composed of a high pressure pump ( $80 \mathrm{bars}, 0.5 \mathrm{~g} . \mathrm{s}^{-1}$ ) for liquid fuels injection. The fluid is heated in an open tubular reactor inside a $6 \mathrm{~kW}$ furnace (maximum temperature of $1900 \mathrm{~K}$ ), which represents the thermal effect of the combustion chamber. The tubular pyrolysis reactor stands for the cooling channel. It is composed of a titanium tube (internal diameter of $4.5 \mathrm{~mm}$ and length of $1000 \mathrm{~mm}$ ) but other materials can be considered (stainless steel, $\mathrm{C} / \mathrm{SiC}$ composite). Numerous sensors (temperature, pressure, mass flow rate) are connected to a data acquisition system $(10 \mathrm{~Hz}, 16$ bits, 48 ways) to obtain the transient variations of these parameters.

\section{Figure 2 should be placed here}

A FTIR spectrometer NICOLET 6700 is available with a specific and innovative identification and quantification method of pyrolysis products under stationary and transient conditions to enable "real-time" and inline measures. The calibration of the FTIR instrument was performed with five products of pyrolysis which have already been analysed in former works (methane, ethene, ethane, propene and propane) [6]. The spectrometer is equipped with a DTGS detector, a $\mathrm{KBr}$ beamsplitter and a cell with a pathlength of $0.1 \mathrm{~m}$. It is employed to obtain the absorption spectra every 15 seconds with 4 scans and with a resolution of $0.5 \mathrm{~cm}^{-1}$. A classical least squares (CLS) method is applied to measure reference levels of these gas and the IR bands have been selected to minimize the interferences between absorptions (for methane : 1304-1308 $\mathrm{cm}^{-1}$, for ethene : 2043-2049 $\mathrm{cm}^{-1}$ and 1886 $1890 \mathrm{~cm}^{-1}$, for ethane : $821-823 \mathrm{~cm}^{-1}$ and $1529-1532 \mathrm{~cm}^{-1}$, for propene : $1647-1652 \mathrm{~cm}^{-1}$ and $2963-2971 \mathrm{~cm}^{-1}$, for propane : $2883-2889 \mathrm{~cm}^{-1}$ ). The Series application (real time acquisition) of OMNIC software is used to obtain the evolution of the molar rate of these gases during an experiment with the COMPARER bench. It must be noted that the optical cell (with a volume of $100 \mathrm{~cm}^{3}$ ) is connected to the reactor outlet thanks to a sampling line of $2 \mathrm{~m}$ long. Thus, a time delay exists between the process outlet and the measurement. Furthermore, this sampling line is not flown by the entire mass flow but only by a minor percentage (lower than $1 \%$ of the total flow). This also reduces the measure dynamics. A new system (already tested) to limit this problem will be presented at the end of the paper.

The pyrolysis tests are conducted with successive stationary steps. With liquid fuels, for a given mass flow rate (from $0.05 \mathrm{~g} . \mathrm{s}^{-1}$ to $0.5 \mathrm{~g} . \mathrm{s}^{-1}$ ), the temperature is increased by $50 \mathrm{~K}$ steps from $750 \mathrm{~K}$ to $1100 \mathrm{~K}$ after thermal stabilisation. The outlet pressure is regulated (from 10 bars to 60 bars) and the inlet pressure is measured. After expansion and cooling of the fluid to atmospheric conditions, the liquid and gas phases are sampled to be analysed by Gas Chromatograph and Mass spectrometer (GC/MS) notably. Thanks to mass balance of gas and liquid phases and to chemical quantification of products and of remaining fuel, the pyrolysis rate is determined experimentally [15]. The gasification rate is determined by the ratio of gas quantity at the process outlet on the one of initial fuel at the inlet. The pyrolysis rate characterises the decomposition level and the gasification rate informs on the nature of products. This test methodology enables providing reliable pyrolysis products compositions for different well controlled test conditions (temperature, pressure and mass flow so residence time). Steady state conditions are preferred to transient thermal slope to get well defined configurations for flow in such open tubular reactor. This is notably required to compare decomposition results between several fuels.

\section{Results and discussion}

The RESPIRE code outputs are all the physical and chemical variables involved in the simulation of the cooling process. The inputs of the code are the inlet temperature, pressure and mass flow rate such as the geometric data and material properties of the reactor. The computations are firstly conducted in the same manner as the experiments are done, that is to say the boundary conditions are those measured experimentally. The pressure is given around 60 bars, the mass flow rate around $0.1 \mathrm{~g} . \mathrm{s}^{-1}$ and the temperature is increased by successive stationary steps during the experiments (Figure 3a). The thermal profile inside the furnace is not uniform due to border effect. The computed fluid temperature shows a similar profile but which is shifted and its maximum is about $90 \mathrm{~K}$ lower than the one of the furnace. In the last part of the reactor, the fluid is at higher temperature than the walls and the heat flux is inverted. This thermal furnace profile is used as an input for computations in steady state conditions (NANCY code, [18], [23]) or in transient conditions (RESPIRE), as it can be done with 2D (or 3D, if gravity is important in the COMPARER tube) coupled simulations [23][24] of this experiment. The fluid is injected as a liquid, it is heated and then it is pyrolysed inside the reactor placed in the furnace. The open reactor in which the continuous pyrolysis takes place is a fully one dimensional system. It can be considered by the present RESPIRE code if the thermal gradients inside a cross-section of the reactor are neglected. Experimental measures have shown a thermal gradient lower than $1 \mathrm{~K}$ inside the furnace at a given longitudinal position but the gradients inside the fluid 
flow are estimated to be higher [6]. The maximum fluid temperature in the process is found in the middle of the reactor (Figure 3a), around $500 \mathrm{~mm}$ to $600 \mathrm{~mm}$.

\section{Figure 3 should be placed here}

During the thermal increase (transient phenomena), numerical data can be easily analysed while the experimental one are more difficult to use even if transient analysis will be conducted in the present paper. For each stationary thermal step, a pyrolysis rate can be estimated depending on the fuel mass fraction at the process outlet. Time history of maximum fluid temperature, residence time and fuel mass fraction are given numerically (Figure 3b). The maximum temperature is found near the middle of the oven (as shown in Figure 3a). The fuel mass fraction is the one at the process outlet. It is quite the same as the one found where the fluid temperature is maximum. It has already been shown that no composition variation is observed during the cooling of the fluid after reaching its maximum temperature [2]. The overall residence time (left y-axis on Figure 3b) is estimated and it appears to decrease during the experiments due to the thermal and chemical effects. The residence time is obtained only by computation because it can not be measured experimentally. It is composed of three parts, which are clearly visible on Figure 4, where the repartition of residence time along the channel is given in percent. The first part (about $80 \%$ of the total residence time for about a third of the furnace) is linked to the heating of the incoming pure fuel (here $\mathrm{n}$ dodecane). The liquid phase (about $50 \%$ of the residence time) turns into supercritical fluid (30\% of the residence time for the same furnace length). Then the third of the reactor, which is in the middle, represents about $10 \%$ of the total residence time; that is to say only $3 \mathrm{~s}$ to pyrolyse the fluid. The last third of the furnace corresponds to the passive cooling of the pyrolysed mixture in the outlet "cold" part of the reactor (as seen in Figure 3a). No chemical reaction of pyrolysis is observed in this last part. This cold part is not representative of a real SCRamjet engine but it does not impact on the results obtained in laboratory conditions.

The mass flow rate should be constant in stationary incompressible flow (the integrated area from both side of the constant dotted line should be close to zero). However, under such transient compressible conditions with supercritical multispecies flow, it can vary along the reactor and with the time (Figure 4). A line for a constant mass flow is presented to highlight the flow accelerations and decelerations. A strong accumulation (mass flow rate decrease) is observed in the first half of the reactor because of the compressibility of supercritical pure n-dodecane. When reaching a high enough fluid temperature ( $90 \%$ of the maximum temperature), the pyrolysis appears and the mass flow rate increases (the accumulated mass is accelerated). In the last third of the process, the entire mixture is supercritical due to the high pressure and it is mainly composed of light species such as methane and ethylene (80\% of pyrolysis rate in the conditions of Figure 4). This explains the draining of the reactor. Of course, the mean mass flow rate in the reactor should be almost constant under stationary conditions. In fact, it varies of about $10 \%$. This is due to the experimental inlet mass flow rate which is not constant in time due to the piston pump system.

\section{Figure 4 should be placed here}

Finally, it is chosen to plot the mass fractions of the most important species at the process outlet (light hydrocarbons from $\mathrm{CH}_{4}$ to $\mathrm{C}_{3} \mathrm{H}_{8}$ and the initial fuel) as a function of time or temperature (Figure 5a). Of course, the sum of all computed mass fractions is equal to one but here not all the species are plotted. It has been shown in previous work that the chemical composition does not change after the maximum temperature is reached in the process and despite the cooling of the fluid at the process outlet in the "cold" part of the furnace [2]. This is visible in Figure 5b. The presented species are the major one at high temperature and they are all present in the gas phase after cooling down and expansion of pyrolysis products at ambient normal conditions. The propane quantity decreases for temperature over $900 \mathrm{~K}$ (Figure 5a) and the propylene one should also decrease over $1000 \mathrm{~K}$ while the other species only increase (in the range of temperature observed experimentally). Obviously, the methane and hydrogen should continue to increase while the ethane and ethylene would decrease for high temperature (over $1100 \mathrm{~K}$ ); finally the methane should decrease over $1500 \mathrm{~K}$ [2].

These observations on the pyrolysis are applicable to all fuels which are considered in the paper because they are related to the secondary reaction mechanism. The primary mechanism is dedicated to each fuel but they produce the same species on which the secondary mechanism is based. While the n-dodecane is the heavier molecules, the primary mechanisms of other fuels correspond to the secondary mechanism of n-dodecane.

\section{Figure 5 should be placed here}

\subsection{Standard experimental configuration and numerical comparison}

Comparing several fuels under the same pyrolysis conditions, enables to estimate their respective cooling activity but it is also the starting point to conduct combustion study to predict the engine thrust and to observe the 
thermal transient impact on the cooling channel along the engine. Depending on the pyrolysis products which are injected in the combustion chamber, the ignition delay will differ and the heat production also. This modifies the heat distribution along the chamber, thus the fuel pyrolysis in the cooling channel. This explains how both reactive flows are coupled.

Four synthetic and aeronautic fuels (n-heptane, n-decane, n-dodecane and kerosene) have been considered experimentally in the conditions described above. For all of them, the same chemical mechanism is used to simulate the pyrolysis encountered in the one dimensional tubular reactor. In addition to the deep understanding of the phenomena involved in the pyrolysis process as detailed before to better analyse the experimental results, the numerical code can be compared to FTIR experimental measures to help validating this measuring technique.

The FTIR quantitative results are expressed in term of molar fraction relatively to the gaseous products only (it is not possible in the offline optical cell to detect the liquid phase of the pyrolysis products). An example is given for the n-dodecane pyrolysis at 60bars, $0.1 \mathrm{~g} . \mathrm{s}^{-1}$ with titanium reactor (Figure 6a). For furnace temperature lower than $900 \mathrm{~K}$, almost no gas product is detected. Then, the signal increases with the temperature because of pyrolysis. The FTIR method has been validated in previous work with GC/MS analysis [22]. It was shown that the method is accurate by $2 \mathrm{~mol} . \%$ if the gasification rate is high enough to reach a mole fraction of the compound of $4 \%$ or higher in the overall pyrolysis products. Thus, for low gasification rate (in case of no or low pyrolysis), the FTIR signal presents mole fraction close to zero while it should not because if gas is produced, the sum of the quantity of its compounds must reach $100 \%$. This is the limitation of this sampling method for FTIR measures. The numerical results do not suffer from this point (Figure 6b). Even for almost no pyrolysis (rate lower than $0.1 \%$ ), the propane quantity (the heavier gas product in the standard laboratory conditions) reaches $60 \%$ and the ethane one about $40 \%$ while their mass fractions in the overall mixture are negligible (much lower than $1 \mathrm{ppb}$ ). Consequently, even fluid temperature around $750 \mathrm{~K}$ (2000 s of experimental time) presents a production of methane to propane while none is detected with FTIR. For high fluid temperature (over $900 \mathrm{~K}$ ), the FTIR and RESPIRE results are in quite good agreement. The time which is necessary to renew the optical cell, the so-called "optical cell turnover time", is linked to the gasification rate, thus to the process activity. The FTIR signal is observed after $4000 \mathrm{~s}$ and more significantly after $8000 \mathrm{~s}$ because for this latest time of experiment, the turnover time is about $100 \mathrm{~s}$, which is deeply acceptable for stationary thermal steps of thousand seconds or more.

\section{Figure 6 should be placed here}

Analytic calculation has been done with first order ordinary differential equation to try understanding the delay and the reduction of the FTIR signal in the experimental conditions. For this purpose, the classical equation of the zero dimensional transient molar fraction, expressed as a function of the volume of the optical cell and of the related volume flow rate, is considered (Eq. 5) with the corresponding solution (Eq. 6).

$$
\begin{gathered}
\frac{d X_{\text {cell }}(t)}{d t}=\frac{Q_{\text {cell }}(t) X_{\text {inlet }}(t)}{V_{\text {cell }}}-\frac{Q_{\text {cell }}(t) X_{\text {cell }}(t)}{V_{\text {cell }}} \\
X_{\text {cell }}(t)=e^{-\int_{0}^{t} \frac{Q_{\text {cell }}(x)}{V_{\text {cell }}} d x}\left(X_{0}+\int_{0}^{t} \frac{Q_{\text {cell }}(x) X_{\text {inlet }}(x)}{V_{\text {cell }}} e^{\int_{0}^{x} \frac{Q_{\text {cell }}(u)}{V_{\text {cell }}} d u} d x\right)
\end{gathered}
$$

with $X_{\text {cell }}$ the molar fraction of the considered specie in the optical cell which should be measured by the FTIR, $X_{\text {inlet }}$ the incoming molar fraction of the considered specie at the inlet of the optical cell, $Q_{\text {cell }}$ the volume flow rate in the optical cell and $V_{\text {cell }}$ the volume of the optical cell.

By using the non constant flow rate measured in the FTIR line (due to varying gasification rate), the molar fraction of methane in the FTIR can be deduced from the one computed by RESPIRE at the process outlet (Figure 7). Obviously, the analytical solution is close to the experimental data and this confirms the reason of numericalexperimental discrepancy. For experimental time higher than $8000 \mathrm{~s}$, both experimental and numerical results are in fair agreement.

\section{Figure 7 should be placed here}

The same configuration ( 60 bars, 0.1 g.s ${ }^{-1}$ with $1 \mathrm{~m}$ long titanium reactor of $4.5 \mathrm{~mm}$ inner diameter) has been considered experimentally and numerically for $\mathrm{n}$-heptane, n-decane and kerosene from $550 \mathrm{~K}$ to $750 \mathrm{~K}$ of setup furnace temperature. The mole fractions relative to the gas phase is compared between FTIR and RESPIRE for each 
fuel (Figure 8). The numerical results obtained for heptane (Figure 8a,b) are not satisfactory because the main pyrolysis products are methane and ethylene while the other products quantities are of the order of few mol.\%. A second computation has been conducted with other temperature, pressure and flow rate data thanks to another experimental test (a higher maximum temperature is reached). A much better agreement is found between FTIR (Figure 8c) and numerical results (Figure 8d) notably for the methane, ethylene and ethane formation (discrepancies lower than $5 \mathrm{~mol} . \%$ ). The results obtained for the n-decane are interesting (Figure 8e,f) because the same phenomena between FTIR and RESPIRE data is visible (major formation of ethylene and ethane). The composition found for kerosene pyrolysis products is not of good agreement (Figure 8g,h), notably due to high numerical ethylene formation, despite the correct prediction for other species (over 5 mol. $\%$ of discrepancy). These poor results can be due to the secondary kinetic mechanism of the n-dodecane which is used for the other fuels instead of appropriate primary mechanism which should be established especially for each initial composition. This indicates that the free radical scheme is not suitable for the hydrocarbon fuels which were tested. It would need to be improved. The constant concentrations of two major products are questionable for $\mathrm{n}$-decane.

The mass fractions of the gaseous species at ambient conditions can increase (formation) but also decrease (consumption) for all the fuels (Figure 9). This is a qualitative good point for the mechanism. Furthermore, the species mass fractions reach a level of few wt.\% to almost $40 \mathrm{wt} . \%$, which is of the right order in these pyrolysis conditions. The mass fractions of gases found for heptane (Figure 9a) are higher because the gas products are the final ones during pyrolysis. Considering the second test with heptane gives more information. The consumption of the high ethylene content is observed (Figure 9b) and ethane is also decomposed while the methane is produced in large part. This is qualitatively reasonable. The production of species for the decane (Figure 9c) is of the same order than for n-dodecane (Figure 9d) but two products only are found in majority for decane while several compounds are experimentally analysed. The kerosene reaches a lower pyrolysis rate and the main product is the ethylene while the other species are all of the same order (few wt.\%) (Figure 9e).

\section{Figure 8 should be placed here}

\section{Figure 9 should be placed here}

The discrepancies between the hydrocarbon fuels is not due to the level of pyrolysis because they are all pyrolysed up to $70 \mathrm{wt} . \%$ to $80 \mathrm{wt} . \%$ (Figure 10a). But this high production of major gas products for heptane and decane clearly differs from dodecane, which presents a lower gasification rate for the same pyrolysis level. The kerosene presents quite a strange trend and this should be more precisely investigated. At this stage, the multicomponent nature of the initial fuel is probably responsible for that. A good agreement is found with experimental data for dodecane and heptane notably. Whatever the test conditions, the two tests for the heptane present similar trend, which is satisfying. Furthermore, the pyrolysis rate is not only dependent on the temperature but also on the fuel nature (Figure 10b). Numerically, the n-heptane is the most stable, then the decane and finally the dodecane. This is in good agreement with estimation of rate constant which increases with the carbon number [25]. This is quite more complicated for the kerosene depending on the initial composition and additives.

\section{Figure 10 should be placed here}

Both numerical cases with $n$-heptane give almost exactly the same pyrolysis rate curve than experimental data of the first test. The second experimental test shows a pyrolysis rate divided by a factor 7 for the same temperature, or a thermal shift of $50 \mathrm{~K}$ for the same pyrolysis rate. This experimental result is not confirmed by the computation and it is judged to be not pertinent. Thus, the theoretical higher stability of light hydrocarbons, which is found in the literature [8],[10] is not obvious. However, the pyrolysis rates obtained numerically roughly corresponds to the literature. Pant \& Kunzru [8] get pyrolysis rate of about $15 \%$ with heptane at $950 \mathrm{~K}$ (20 wt $\%$ with RESPIRE), Zeppieri et al. [25] show a pyrolysis rate of $100 \%$ at $1050 \mathrm{~K}$ and Herbinet [10] found rate of about $55 \mathrm{wt} \%$ for dodecane pyrolysis at $870 \mathrm{~K}$ ( $45 \mathrm{wt} \%$ with RESPIRE). Of course, the pressure, the residence time and reactor nature impact on these results. For decane and dodecane, a thermal shift up to $100 \mathrm{~K}$ is visible between numerical and experimental data. This is due to the kinetic mechanism which is known to start pyrolysis process for temperature $50 \mathrm{~K}$ to $100 \mathrm{~K}$ lower than for experimental one [15]. The kerosene, modelled by a mixture of about 20 compounds on the basis of experimental GC/MS analysis [14], give similar results as the decane. This is satisfying because the decane is generally considered to model the kerosene combustion notably (which takes its pyrolysis into account as the fuel starts to decompose before burning, see section 3.3).

\subsection{Comparison of cooling ability and combustion efficiency of several fuels}


The precedent numerical results have been analysed in relationship with the fuel physical and chemical properties. This approach enables to understand the main characteristics which impact on the cooling effect. This could help to design a new fuel, which would be interesting for both cooling and propulsive application (probably by mixing existing fuels). The heat fluxes absorbed along the channel has been determined for each fuel as a function of maximum fluid temperature (Figure 11). It is not dependant on the fluid nature but only on the fluid temperature. The maximum Reynolds number in the reactor increases by a factor 10 or more during the simulations. This is due to the variation of dynamic viscosity and density within the pyrolysis process. The heat capacity firstly depends on the fluid temperature (Figure 12a) and then on the chemical composition. During the pyrolysis of heptane, decane and kerosene (for which the major compounds only are consider to estimate the pyrolysis rate), the heat capacity is almost constant and the one for dodecane slightly increases due to a thermal increase (Figure 12b). A factor 2 is observed with pure fuels on the heat capacity increase due to the temperature (Figure 12b). The density is obviously greater for heavy hydrocarbons than for light ones and it decreases with the temperature during the pyrolysis (Figure $12 \mathrm{c})$. The density of kerosene between $300 \mathrm{~K}$ and $500 \mathrm{~K}$ is questionable. Up to one order of magnitude can be found between all the fuels on the dynamic viscosity $\left(10^{-7} \mathrm{~Pa}\right.$.s to $\left.10^{-6} \mathrm{~Pa} . \mathrm{s}\right)$ and this property is mainly a function of temperature (Figure 12d). The kinematic viscosity is of the same order due to density variations. On the basis of these observations, the requirements on the coolant should be the following. The fuel should have a high thermal stability to increase the cooling efficiency as seen in Figure 11a. For a given mass flow rate, it should have a low density to increase both the convective heat exchange and the fluid velocity (decrease of residence time). The viscosity is not really a relevant parameter. Consequently, $\mathrm{C}_{7} \mathrm{H}_{16}$ is probably more interesting than $\mathrm{C}_{10} \mathrm{H}_{22}$, kerosene or $\mathrm{C}_{12} \mathrm{H}_{26}$. Its "higher" stability could make the coke formation issue to be less important.

The heptane pyrolysis products which have been obtained in previous conditions of pyrolysis and for different pyrolysis temperatures $(800 \mathrm{~K}$ to $1000 \mathrm{~K})$ have been studied with air at the stoichiometry under a constant pressure of 2 bars in premixed configuration (Figure 13) with detailed combustion mechanism (kerosene combustion modelled by decane thanks to Dagaut and Cathonnet mechanism, 207 species and 1592 reactions [27]). The ignition time and the final flame temperature are mainly dependent on the initial combustion temperature and not on the initial composition. Nevertheless, for the same initial temperature of combustion of $1000 \mathrm{~K}$, the pyrolysis products obtained at $800 \mathrm{~K}$ present an ignition time $(9 \mathrm{~ms})$ lower than those obtained at $1000 \mathrm{~K}(10 \mathrm{~ms})$. The final temperature is very similar $(10 \mathrm{~K}$ of discrepancy). The differences are much too small to be significant. Consequently, it is assumed that in this range of pyrolysis temperature, the chemical impact on the combustion fuel efficiency is highly reduced. The same conclusions can be drawn from the computation with decane, dodecane and kerosene.

\section{Figure 11 should be placed here}

\section{Figure 12 should be placed here}

\section{Figure 13 should be placed here}

To compare the burning ability of the fuels, the composition of pyrolysis products of the four selected fuels, which have been obtained in the previous test bench conditions at about $1000 \mathrm{~K}$, have been considered for combustion at $1650 \mathrm{~K}$ (initial temperature corresponding to inlet air temperature in case of Mach 6 flight number) and 2 bars with premixed constant pressure configuration (Figure 14). All of them present similar final flame temperature (from $2894 \mathrm{~K}$ for dodecane to $2910 \mathrm{~K}$ for heptane). All the ignition delays are found to be lower than $0.1 \mathrm{~ms}$. The kerosene presents the lowest ignition delay (about $20 \mu \mathrm{s})$ while the dodecane has the highest one $(30 \mu \mathrm{s}$ roughly). This is attributed to the high ethylene content in the kerosene pyrolysis products while the methane is the major specie for dodecane among those which are gaseous at ambient conditions, that is to say the easiest or fastest to ignite. The decane presents higher ethylene content than dodecane but lower than kerosene. The heptane pyrolysis mixture has higher ethylene content than kerosene but its methane concentration is higher and its hydrogen one is lower. Consequently, the kerosene is found to present better combustion behaviour than the other even if they are all very similar. This good behaviour is attributed to the presence of a wide range of hydrocarbons and especially of alkenes and aromatics which favours the production of light species such as ethylene instead of alkane.

\section{Figure 14 should be placed here}

Even if the kinetic model used here was designed to model kerosene, the ignition time of heptane, decane, dodecane and kerosene are coherent in sorting with the experimental or dedicated results. Nevertheless, these discrepancies between the fuels remain quite low. Several studies about ignition delay can be found in the literature and they confirm these results. For example, the n-dodecane and jet-fuel have similar ignition delay (around $20 \mathrm{~ms}$ 
at $1000 \mathrm{~K}$ [28]) and mixtures of decane with pure $\mathrm{O}_{2}$ from $1 \mathrm{~ms}$ to $100 \mathrm{~ms}$ depending on the dilution factor [29] but also on pressure (from $1 \mathrm{~atm}$ to $20 \mathrm{~atm}$ ) and on fuel-air ratio. The same is observed for heptane [30]. Decane and dodecane are very similar considering the flame temperature notably [31]. Other analytical approach can be found to compute the ignition delay and to validate these present calculations [32].

\subsection{Full coupling of fuel pyrolysis and products burning}

In this paragraph, we do preliminary analysis of combustion of the dodecane pyrolysis products. It is the case in an actual engine with regenerative cooling. This was also envisaged from the beginning of the COMPARER project to be able to couple, for an academic detailed experimental study, the pyrolysis reactor with a simple burner and associated measurements.

First of all, a computation of the cooling of a generic SCRamjet combustion chamber (CC) has been conducted in the conditions given in Table 1 with stationary thermal load in the combustion chamber. The coolant is entirely decomposed at the cooling channel outlet due to its temperature around $1300 \mathrm{~K}$ (Figure 15). The CC burned gases flow from the position $1.1 \mathrm{~m}$ to $0 \mathrm{~m}$, which is the coolant inlet position. This is the reason why the CC heat flux is higher in the coolant inlet region. The energy absorbed by the coolant is $2.27 \mathrm{MJ} . \mathrm{kg}^{-1}$, which is very similar to the value found in laboratory conditions. The $\mathrm{n}$-dodecane is heated from $300 \mathrm{~K}$ to $700 \mathrm{~K}$ without pyrolysis (corresponding to the following locations: $0 \mathrm{~m}$ to $0.4 \mathrm{~m}$ ) (Figure 16). This corresponds to a residence time of $3 \mathrm{~s}$, that is to say $87 \%$ of the total residence time. This proportion is highly comparable to the one found for experimental cases (without considering the "cold" part of the furnace which is not representative of the SCRamjet). The pyrolysis from $0 \%$ to $100 \%$ is found in the last two third of the cooling channel (residence time of $0.45 \mathrm{~s}$ ). The formation of $\mathrm{H}_{2}$ and $\mathrm{C}_{2} \mathrm{H}_{2}$ is minor (sum of mass fractions lower than $10 \%$ ) while $\mathrm{CH}_{4}, \mathrm{C}_{2} \mathrm{H}_{4}, \mathrm{C}_{2} \mathrm{H}_{6}, \mathrm{C}_{3} \mathrm{H}_{6}, \mathrm{C}_{3} \mathrm{H}_{8}$ are the major products up to $1000 \mathrm{~K}$. Over $1000 \mathrm{~K}$, the benzene appears in large quantity (witness of the pyrolytic coke formation) and the heavier pyrolysis products like ethane, propylene and propane are consumed to favor the methane formation (up to $22 \mathrm{wt} . \%$ ). Ethylene is consumed over $1200 \mathrm{~K}$. These conclusions are in perfect agreement with experimental and numerical results presented in previous sections. This justify using laboratory conditions to study the SCRamjet cooling.

\section{Table 1 should be placed here}

\section{Figure 15 should be placed here}

\section{Figure 16 should be placed here}

Then, the pyrolysis products composition has been considered to conduct a brief combustion calculation in air at the stoichiometry under constant pressure of $2 \mathrm{~atm}$. The combustion delay is $0.46 \mathrm{~ms}$, which is under the indicative limit considering that it should be lower than $0.1 \mathrm{~ms}$ for SCRamjet configuration [2]. Nevertheless, the maximum flame temperature is $2780 \mathrm{~K}$, which is close to the maximum considered one for this simulation test case (Table 1). Consequently, considering the illustrative purpose of the present study, it is of great interest to study the transient coupling between the fuel pyrolysis during the $\mathrm{CC}$ cooling and its combustion to estimate the CC heat flux on the hot face of the porous wall (described in Figure 1). The thermal load in the combustion chamber is computed thanks to detailed combustion mechanism [27] by assuming a combustion engine performance of unity to estimate the temperature profile in the $\mathrm{CC}$ (the heat exchange coefficient is considered to be stationary but spatially non uniform as used in previous test case, see Table 1).

The pyrolysis products formed in the cooling channel are injected in the combustion chamber while the wall temperature is fixed for the first calculation (Figure 17a). In the first third of the CC (from $1.1 \mathrm{~m}$ to $0.7 \mathrm{~m}$ ), a fuel pyrolysis still appears because the temperature (the one of inlet air around $1000 \mathrm{~K}$ ) is too low depending on the fluid residence time to allow an auto-ignition (Figure 17a). Then, the combustion is observed through the consumption of oxygen while the fuel excess is still pyrolysed to produce methane or hydrogen. This incomplete combustion is confirmed by the large amount of $\mathrm{CO}$ in combustion products. The $\mathrm{CO}_{2}$ is formed in much lower quantity. Due to the lack of oxygen, hydrogen for example is still present at the outlet while it could burn if sufficient amount were furnished (higher than the $1 \mathrm{~kg} . \mathrm{s}^{-1}$ for this example). When considering the temperature computed by the reactive process itself and dividing it by the initial temperature profile (Figure 17b), it decreases slightly along the chamber (from $100 \%$ to $80 \%$ the initial fixed one). This shows that the products are not burned quickly enough due to pyrolysis occurring in the $\mathrm{CC}$ and due to low auto-ignition delay. These first results are qualitatively interesting because they are the first available one in bibliography toward the study of coupled pyrolysis-combustion phenomena in cooled SCRamjet engine. 
Then, a full coupling of detailed fuel pyrolysis and by-products combustion is proposed with heat and mass transfer. After only $105 \mathrm{~ms}$ (Figure 18a), the temperature of the coolant decreases, the rest of n-dodecane is doubled at the channel outlet and the production of light species is reduced even if the ethylene content increases. As a result, the combustion in the CC extinguished (Figure 18b). After the strong temperature decrease, a second zone at the CC outlet (temperature around $1200 \mathrm{~K}$ ) indicates that combustion still occurs. Then, the low auto-ignition delay of pyrolysis products stops the combustion in the $\mathrm{CC}$ and only a low heat release is visible, mainly due to reverse heat flux from the channel. As a conclusion, this example shows how difficult it could be to achieved supersonic combustion with regenerative cooling and how the RESPIRE code can be useful in this way.

Figure 17 should be placed here

Figure 18 should be placed here

\section{Conclusion}

For high speed flight applications, the cooling of porous structures has to be investigated to understand the related coupled phenomenon such as heat and mass transfer, fuel pyrolysis and coke formation. An experimental bench has been settled in the COMPARER project and it allows conducting high temperature and pressure studies $\left(1200 \mathrm{~K}, 60\right.$ bars and $0.5 \mathrm{~g}_{\mathrm{gs}}^{-1}$ ). The RESPIRE code has been used in this paper to give valuable details on the pyrolysis phenomenon and its relationship with heat and mass transfers (convective exchange coefficient, Reynolds number, temperature, residence time). The flow compressibility effect and the production and consumption of pyrolysis products have been shown. A good agreement with transient FTIR measurements is obtained. The discrepancies have been explained and they are notably due to time delay in mass transfers between the process and the measurement point. Analytical work has been proposed in this way. The behaviour of several synthetic and jet fuels have been compared in similar pyrolysis conditions to estimate their cooling efficiency, their composition at the cooling channel outlet and their combustion characteristic. The specific mass energy which can be absorbed by each fuel has been determined. The $\mathrm{n}$-heptane is the most stable fuel for a given temperature while the $\mathrm{n}$-dodecane is the fuel which produces the less gaseous species (from $\mathrm{H}_{2}$ to $\mathrm{C}_{3} \mathrm{H}_{8}$ ) for a given pyrolysis rate. The decane and kerosene (mixture of about 20 compounds) have also been considered numerically and experimentally.

The conversion of thermal energy into chemical one along the channel enables to understand what physical and chemical parameters are important for the design of a fuel, suitable for cooling and propulsive purpose. The Reynolds number increases with the temperature, which is higher for heptane than dodecane for example. This is more interesting for convective heat transfer. Further computations and experiments remain necessary to understand how two successive pyrolysis tests on n-heptane can give so different results while the reproducibility has been widely tested in previous work and it has been estimated around $2 \%$ on the chemical composition. Other detailed kinetic mechanisms should also be tested to investigate pyrolysis for fuels other than $\mathrm{n}$-dodecane.

For each fuel, the combustion of pyrolysis products does not yield to major discrepancies. Nevertheless, the kerosene gives the lower ignition delay $(20 \mu \mathrm{s}$ at $1650 \mathrm{~K})$ among the other fuels in the same conditions. In real SCRamjet cooling conditions with 0 -D calculations, the ignition-delay of $\mathrm{n}$-dodecane pyrolysis products is reasonable and could be in perfect agreement with the requirements if the mass flow rate is reduced (from $65 \mathrm{~g} . \mathrm{s}^{-1}$ to 60 g.s $\mathrm{s}^{-1}$ probably). The flame temperature is in good adequacy to hypersonic flight purpose (flight Mach number 6). Nevertheless, with 1-D fully coupled pyrolysis-combustion approach, the behaviour of the products is not so good. The result of this is that an extinction of the engine appears. Thus, considering such complex configuration with adapted tool is the only way to manage such a difficult and challenging regenerative cooling problem. A parametric study will now be conducted before starting to work on a regulation and control strategy of the engine to precisely estimate the influence of parameters.

\section{Acknowledgments}

The present work was realised with the contribution of the city of Bourges, of the "Conseil Général du Cher", of the "Conseil Régional du Centre", of the FRED, of the FEDER, of the FSE, of MBDA-France and of Y. Parmantier.

The authors want to quote the COMPARER team and especially Guillaume Fau from PRISME laboratory and Marc Bouchez, Bruno Le Naour, Christophe Bonzom and Julien Bertrand from MBDA France.

\section{References}

[1] R S Fry, A century of ramjet propulsion technology evolution, J. Prop. Power, Vol. 20 No. 1 Jan.-Feb, (2004). 
[2] N Gascoin, Etude et mesure de paramètres pertinents dans un écoulement réactif application au refroidissement par endo-carburant d'un super-statoréacteur, Editions Universitaires Européennes, avril 2010, ISBN13: 9786131501074,376 pages.

[3] F Falempin and L Serre, LEA flight test program - status in 2004, 40th AIAA Joint Propulsion Conference, Fort Lauderdale, Florida, 11 - 14 July, (2004), AIAA-2004-3344,

[4] M Bouchez and S Beyer, Ptah-socar fuel-cooled composite materials structure for dual-mode ramjet and liquid rocket engines - 2005 status, 13th Hypersonics Systems and Technologies Conference, (2005) AIAA 2005-3434

[5] K.D. Dahm, P.S. Virk, R. Bounaceur, F. Battin-Leclerc, P.M. Marquaire, R. Fournet, E. Daniau, M. Bouchez, Experimental and modelling investigation of the thermal decomposition of n-dodecane, J Anal Appl Pyrol, Vol 71 (2004) 865-881.

[6] N Gascoin, P Gillard, E Dufour and Y Touré, Validation of transient cooling modeling for hypersonic application, J Thermophys Heat Tr, Vol. 21 N 1 Jan-Mar (2007) 86-94

[7] N Gascoin, P Gillard, S Bernard, G Abraham, M Bouchez, E Daniau, Y Touré, Measurements for fuel reforming for scramjet thermal management and combustion optimization : status of the COMPARER project, 14th Hypersonic Systems and Technologies Conference, Canberra, Australia, 6-9 Nov, (2006), AIAA-2006-8005.

[8] KK Pant, D Kunzru, Pyrolysis of n-heptane : kinetics and modelling, J Anal Appl Pyrol, 36 (1996) 103-120

[9] Z Wang, Y Guo, R Lin, Effect of triethylamine on the cracking of heptane under a supercritical condition and the kinetic study on the cracking of heptane, Energ Convers Manage, 49 (2008) 2095-2099

[10] O Herbinet, P.M Marquaire, F Battin-Leclerc, R Fournet, Thermal decomposition of n-dodecane: Experiments and kinetic modelling, J Anal Appl Pyro, Volume 78, Issue 2, March (2007), pp 419-429.

[11] R.P Nageswara, D Kunzru, Thermal cracking of JP-10 : Kinetics and product distribution, J Anal Appl Pyrol, 76 (2006) 154-160

[12] J Yu, S Eser, Supercritical-phase thermal decomposition of binary mixtures of jet fuel model compounds, Fuel 79 (2000) 759-768

[13] Z Wang, Y Guo, R Lin, Pyrolysis of hydrocarbon fuel ZH-100 under different pressures, J Anal Appl Pyrol, Volume 85, Issues 1-2, May, (2009), Pp 534-538

[14] G Abraham, Etude et développement d'une méthode d'analyse par spectroscopie infrarouge appliquée à la pyrolyse d'hydrocarbures en conditions supercritiques et transitoires, Ph.D. Thesis, December 2009, University of Orléans, France

[15] N Gascoin, P Gillard, S Bernard, E Daniau, M Bouchez, Pyrolysis of Supercritical Endothermic Fuel: Evaluation for Active Cooling Instrumentation, IJCRE, Vol. 6, 2008, A7, Ed. The Berkeley Electronic Press

[16] N Gascoin, P Gillard, S Bernard, M Bouchez, Characterisation of coking activity during supercritical hydrocarbon pyrolysis, Fuel Process Technol, Vol. 89, Issue 12, December, (2008), pp1416-1428.

[17] X.Q Guo, C.Y Sun, S.X Rong, G.J Chen., T.M Guo. Equation of State Analog Correlations for the Viscosity and Thermal Conductivity of Hydrocarbons and Reservoir Fluids, J Petrol Sci Eng, 30 (2001) 15-27.

[18] E Daniau, M Bouchez, N Gascoin, SCRAMJET Active Cooling Analysis Using n-dodecane as a Generic Endothermic Fuel, Thermochemical Processes in Plasma Aerodynamics, St Petersburg, Russia, 12-14 July, (2004).

[19] N Gascoin, P Gillard, Y Touré, S Bernard, E Daniau, M Bouchez, Modélisation Hydraulique et Thermique d'un Fluide Supercritique avec Pyrolyse dans un Canal Chauffé: Prédimensionnement d'une Etude Expérimentale, Congrès Français de Thermique, SFT, Reims, France, 30 mai - 2 juin, (2005).

[20] N Gascoin, P Gillard, Y Touré, E Daniau, S Bernard, M Bouchez, Modélisation d'un Statomixte Refroidi par Endocarburant Supercritique : Couplage Thermique-Chimie et Transferts de Matière, Récents Progrès en Génie des Procédés, $\mathrm{N}^{\circ}$ 92, Ed. Lavoisier, (2005).

[21] N Gascoin, P Gillard, M Bouchez, Characterization of Supercritical Reactive Flow for Hypersonic Real-Time Application, 16th Hypersonic Systems and Technologies Conference, Bremen, Germany, (2009), AIAA 2009-7375

[22] G Abraham, N Gascoin, S Bernard, P Gillard, M Bouchez, J Bertrand, B Le Naour, Measurements for fuel reforming for scramjet thermal management and combustion optimization: 2009 status of the COMPARER project, 16th Hypersonic Systems and Technologies Conference, Bremen, Germany, (2009), AIAA 2009-7373

[23] M Bouchez, E Dufour, E Daniau, Semi-empirical and CFD analysis of actively cooled dual-mode ramjets : 2006 status, 14th Hypersonic Systems and Technologies Conference, Canberra, Australia, (2006) AIAA-2006-8073

[24] M Bouchez, E Dufour, F Cheuret, J Steelant, P Grenard, J.A Redford, N.D Sandham, G.T Roberts, A Passaro, D Baccarella, M Dalenbring, J Smith, Material-Aero-Thermal Interaction Computations in the ATLLAS European Programme, 44th Joint Propulsion Conference and Exhibit, Hartford, CT, July 20th-23rd, (2008), AIAA-2008-4670. [25] M Watanabe, T Adschiri, K Arai, Overall Rate Constant of Pyrolysis of n-Alkanes at a Low Conversion Level, Ind. Eng. Chem. Res, Vol. 40, No. 9, (2001), pp2027-2036 
[26] S.P Zeppieri, S.D Klotz, F.L Dryer, Modeling concepts for larger carbon number alkanes : a partially reduced skeletal mechanism for n-decane oxidation and pyrolysis, Proceeding of the Combustion Institute, 28 (2000) 15871595

[27] P. Dagaut, M Cathonnet. The ignition, oxidation, and combustion of kerosene: A review of experimental and kinetic modeling, Prog Energ Combust, 32, (2006), 48-92.

[28] S.S Vasu, D.F Davidson, Z Hong, V Vasudevan, R.K Hanson, n-Dodecane oxidation at high-pressures: Measurements of ignition delay times and $\mathrm{OH}$ concentration time-histories, Proceedings of the Combustion Institute 32 (2009) 173-180

[29] X You, F.N Egolfopoulos, H Wang, Detailed and simplified kinetic models of n-dodecane oxidation: The role of fuel cracking in aliphatic hydrocarbon combustion, Proceedings of the Combustion Institute 32 (2009) 403-410

[30] B Imbert, F Lafosse, L Catoire, CE Paillard, B Khasainov, Formulation reproducing the ignition delays simulated by a detailed mechanism: Application to n-heptane combustion, Combust Flame 155 (2008) 380-408

[31] K Kumar, C.-J Sung, Laminar flame speeds and extinction limits of preheated n-decane/O2/N2 and ndodecane/O2/N2 mixtures, Combust Flame 151 (2007) 209-224

[32] K Kumar, G Mittal, C.J Sung, Autoignition of n-decane under elevated pressure and low-to-intermediate temperature conditions, Combust Flame 156 (2009) 1278-1288

[33] N Gascoin, G Fau, J Bioud, P Gillard, Permeation of inert and supercritical reactive fluids through metallic and composite media, 46th Joint Propulsion Conference \& Exhibit, Nashville, USA, July (2010), AIAA-2010-6551. 
Table 1. Conditions of the simulation of the SCRamjet cooling.

\begin{tabular}{ll}
\hline CC length & $1.1 \mathrm{~m}$ \\
CC width & $0.212 \mathrm{~m}$ \\
CC wall thickness & $0.003 \mathrm{~m}$ \\
Cooling channel structure & Pin fins \\
Coolant nature & $\mathrm{n}-\mathrm{C}_{12} \mathrm{H}_{26}$ \\
Coolant flow rate & $0.065 \mathrm{~g} \cdot \mathrm{s}^{-1}$ \\
Flight Mach number & 6 \\
CC structure nature & $\mathrm{C} / \mathrm{SiC}$ generic composite \\
CC temperature & Non uniform stationary profile from $1650 \mathrm{~K}$ to $3000 \mathrm{~K}$ \\
CC heat exchange coefficient & Non uniform stationary profile from $800 \mathrm{~W} \cdot \mathrm{m}^{-2} \cdot \mathrm{K}^{-1}$ to $1500 \mathrm{~W} \cdot \mathrm{m}^{-2} \cdot \mathrm{K}^{-1}$ \\
\hline \hline
\end{tabular}




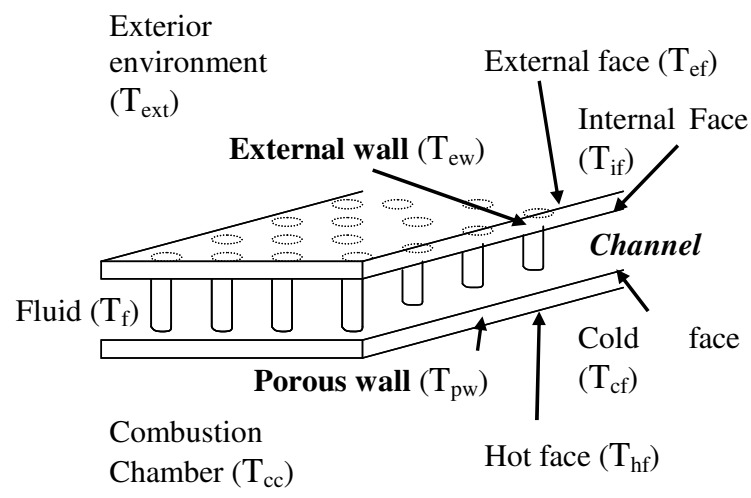

Figure 1. Example of chemical reactor geometry with adopted notations. 


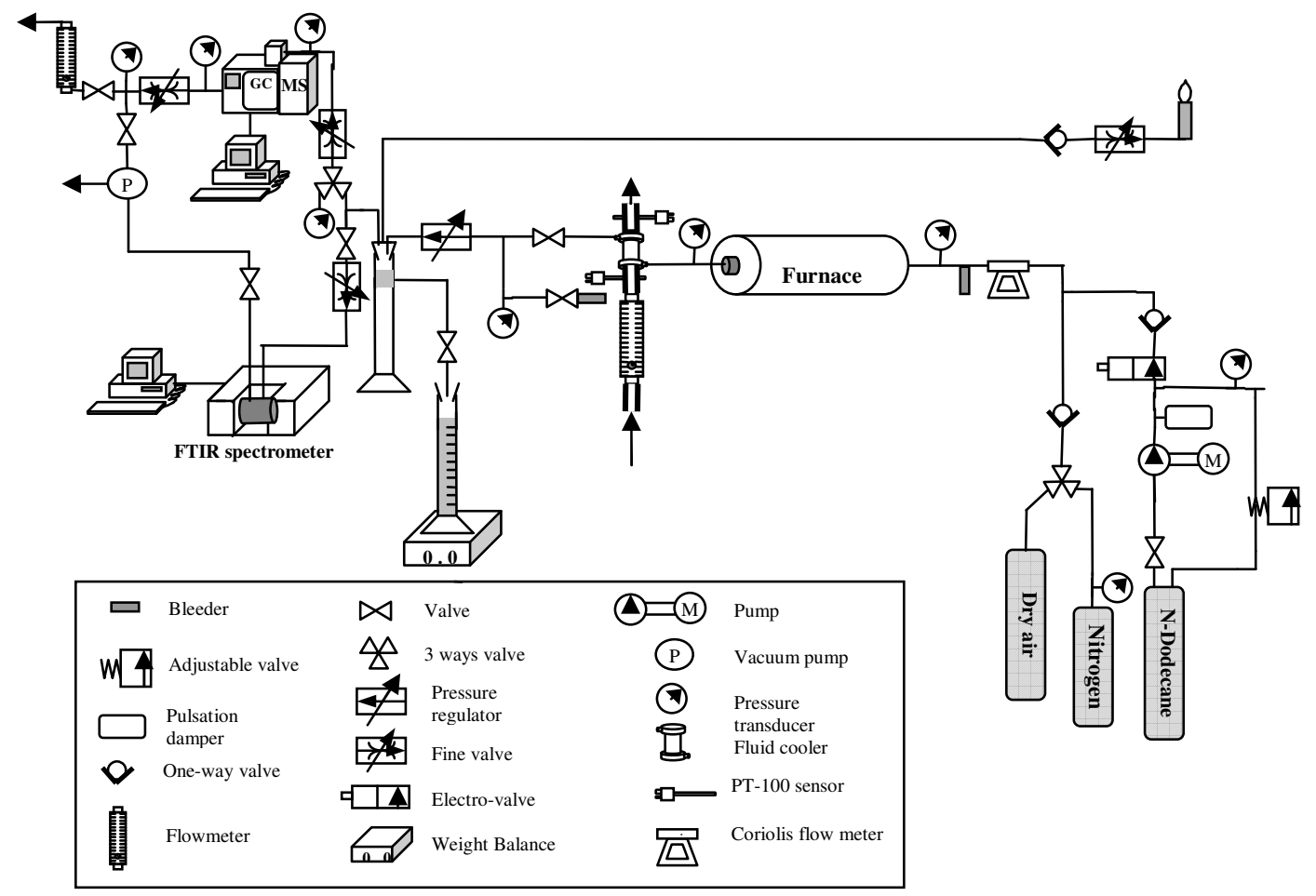

Figure 2. Schematic of the COMPARER test bench at the PRISME laboratory in Bourges. 

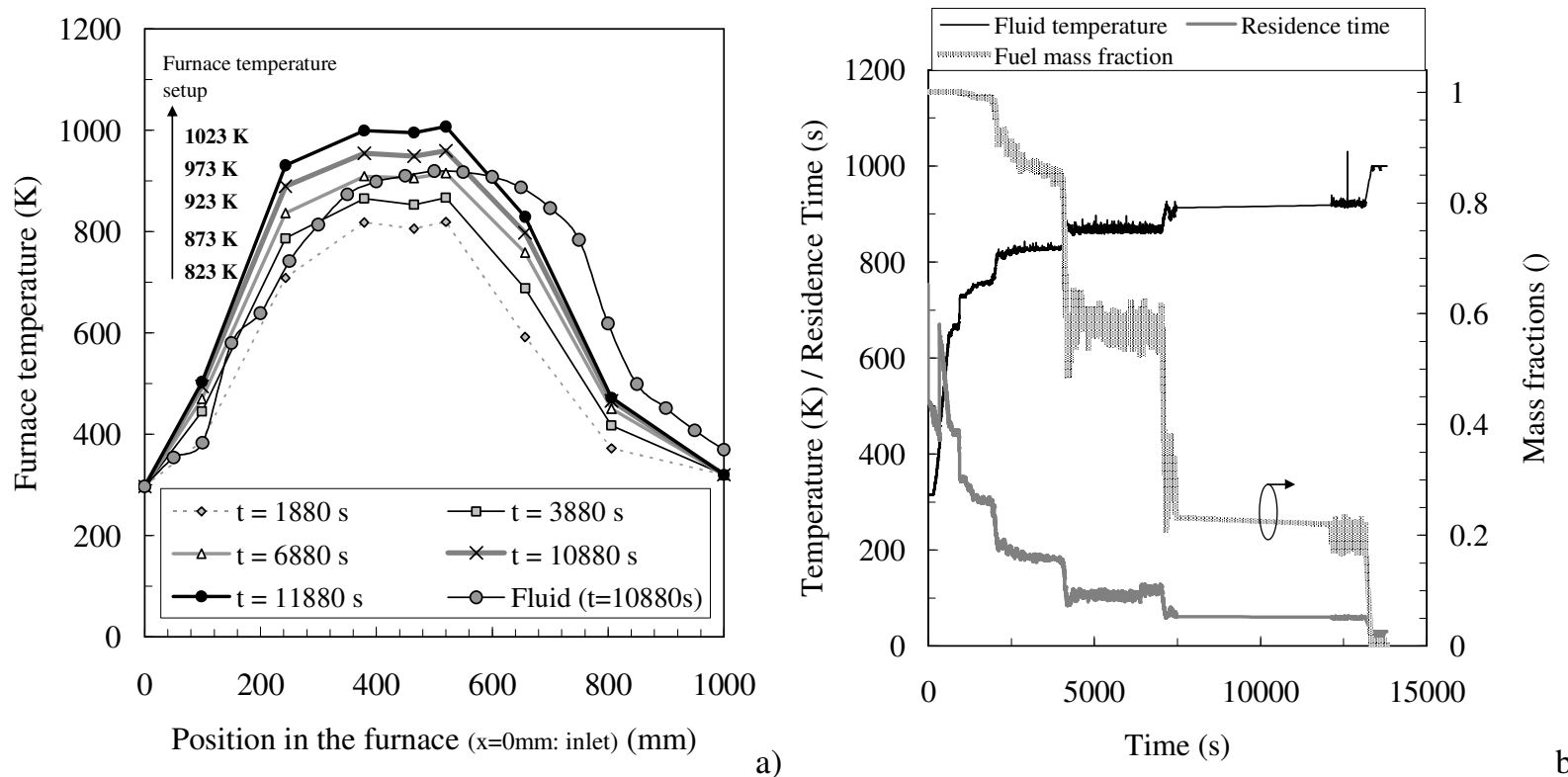

Figure 3. Thermal profile inside the furnace for several thermal steps at different time steps (a) and maximum fluid temperature inside the process with related fuel mass fraction for n-dodecane pyrolysis with titanium reactor $(b)$. 


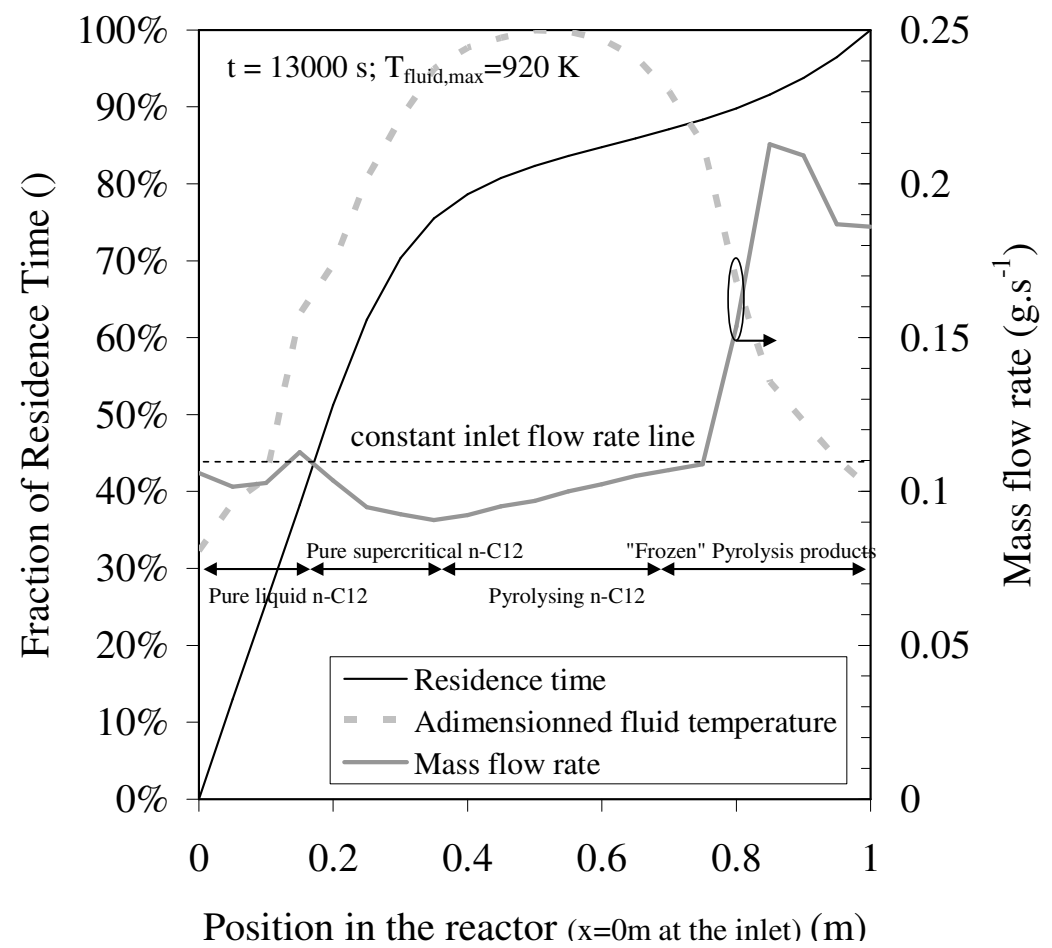

Figure 4. Distribution of the residence time in the process and accumulation of fluid along the reactor during n-dodecane pyrolysis at 60 bars and $0.1 \mathrm{~g} . s^{-1}$ for a furnace thermal step of $950 \mathrm{~K}$. 

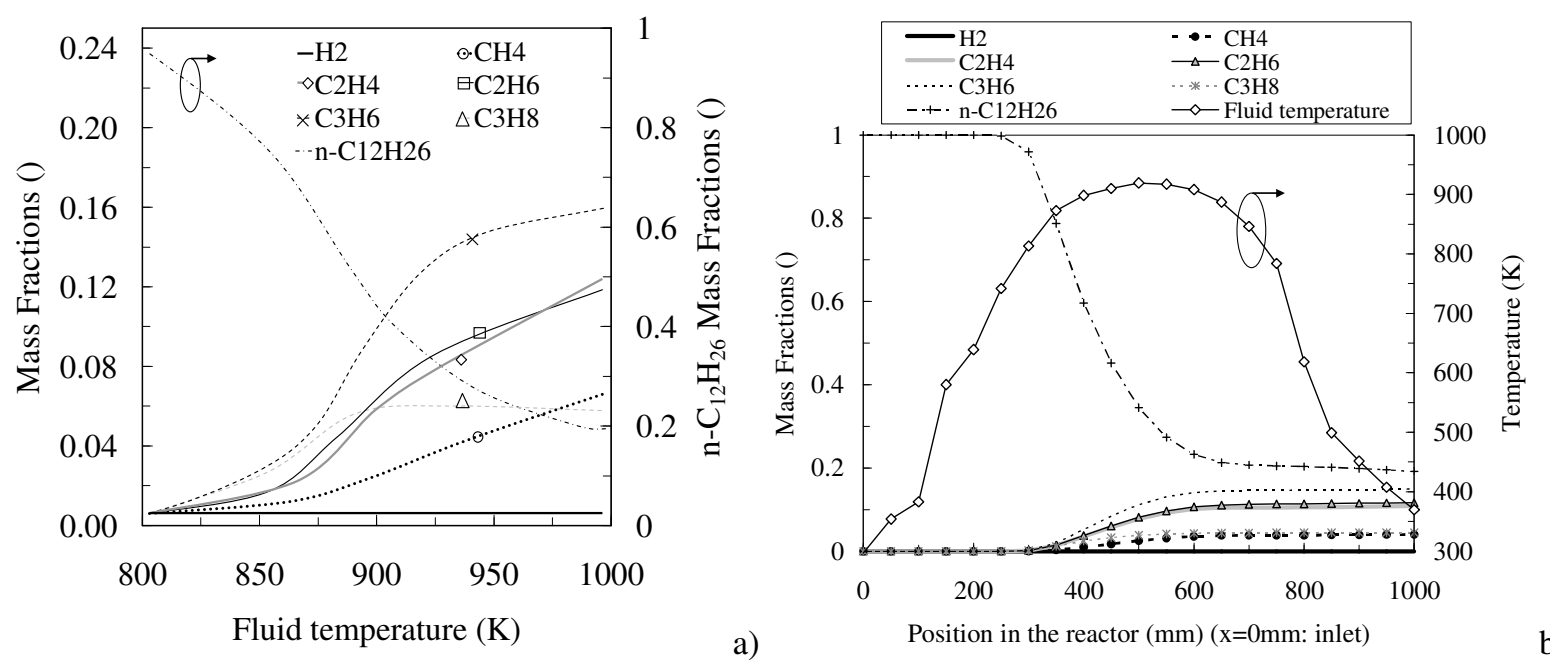

Figure 5. Pyrolysis of n-dodecane and main final products formation at $60 \mathrm{bars}, 0.01 \mathrm{~g} . \mathrm{s}^{-1}$ in titanium reactor as a function of temperature (a) and along the channel at furnace temperature setup of $973 \mathrm{~K}(\mathrm{t}=10880 \mathrm{~s}$ on Figure 3a) (b). 

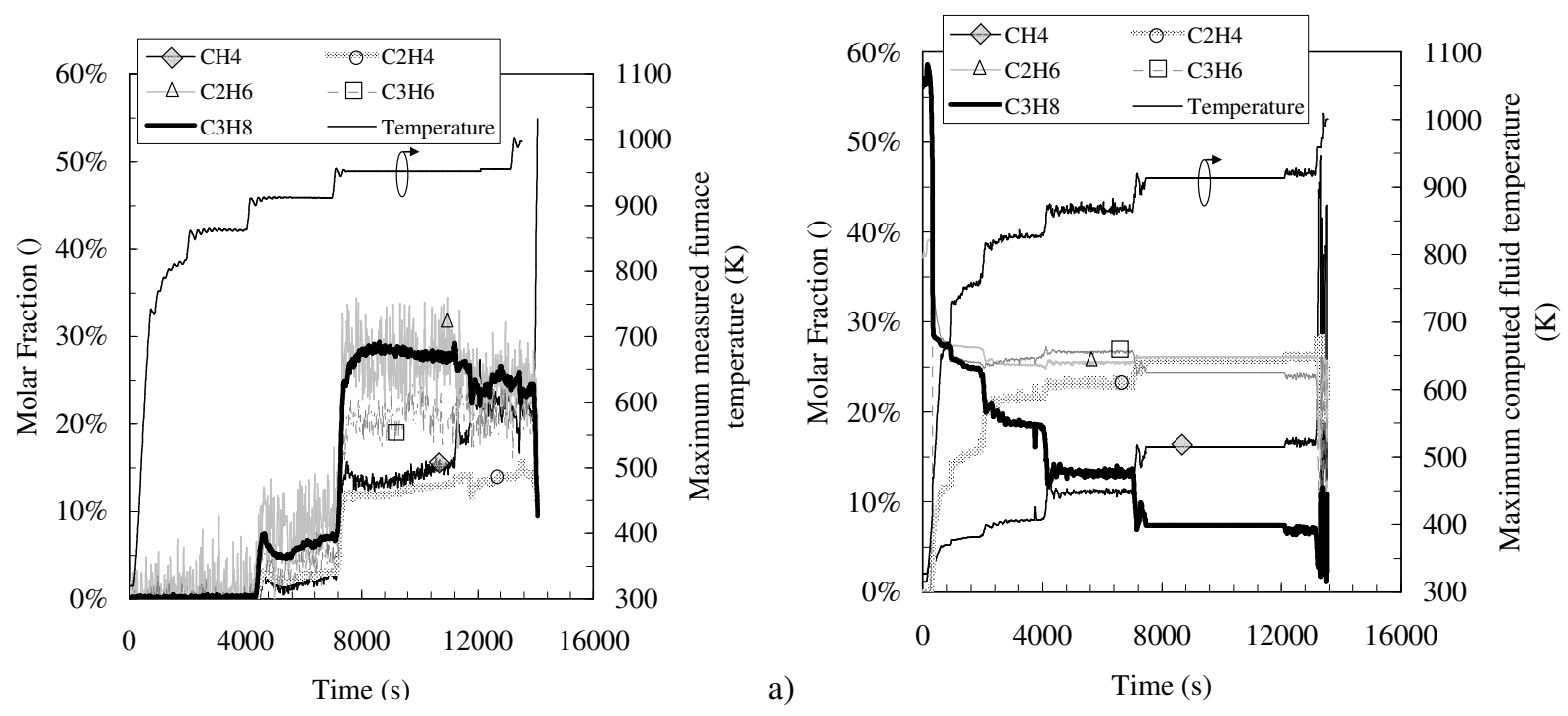

b)

Figure 6. Molar fraction of gaseous pyrolysis products measured by FTIR (a) and computed by RESPIRE (b). 


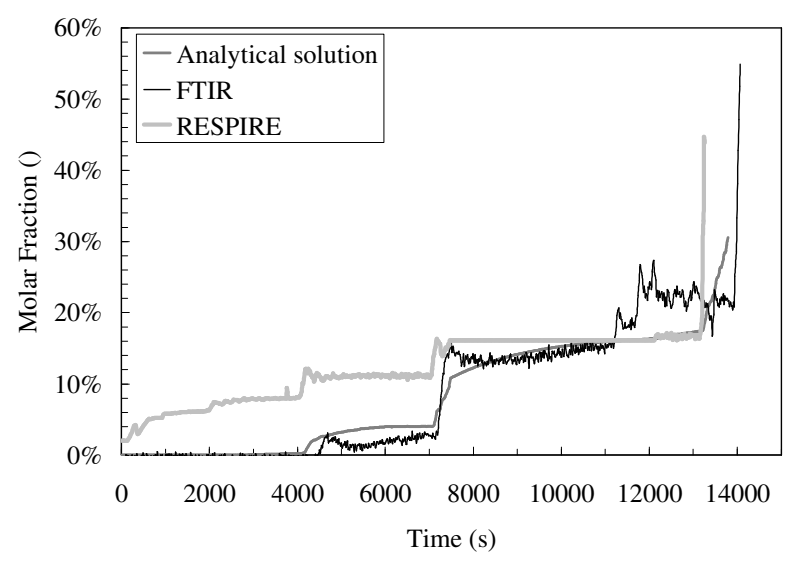

Figure 7. Methane molar fraction measured by FTIR, computed by RESPIRE and estimated numerically in the FTIR after correction with analytical formula. 

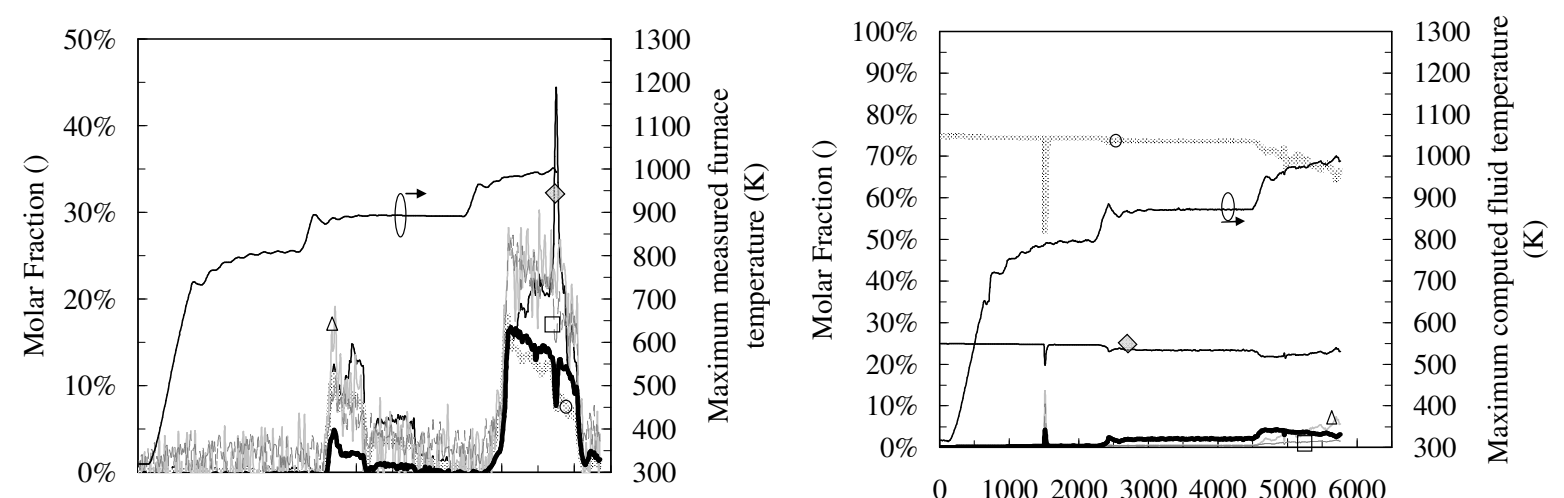

0100020003000400050006000

Time (s)
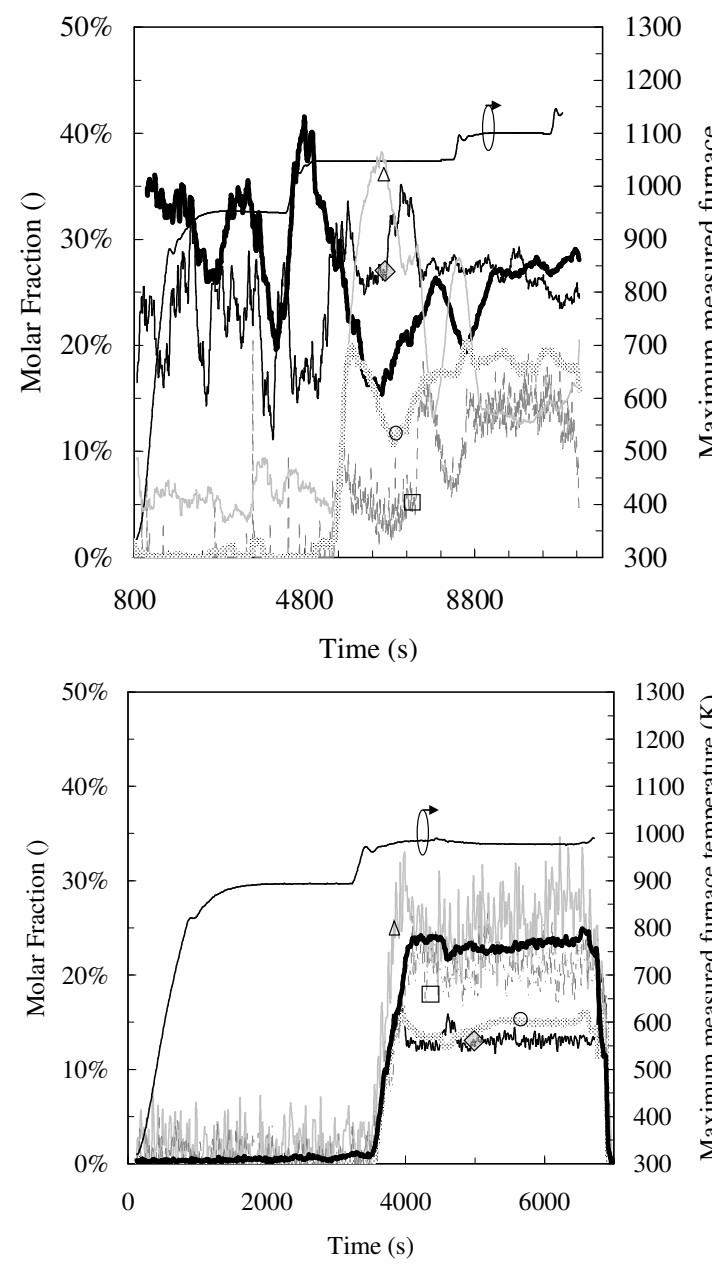

a)
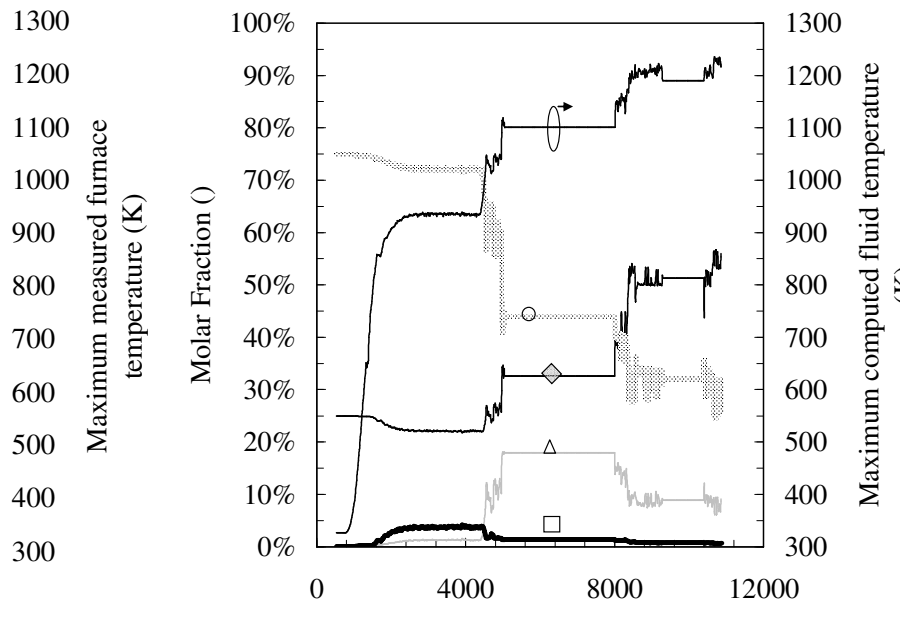

c)

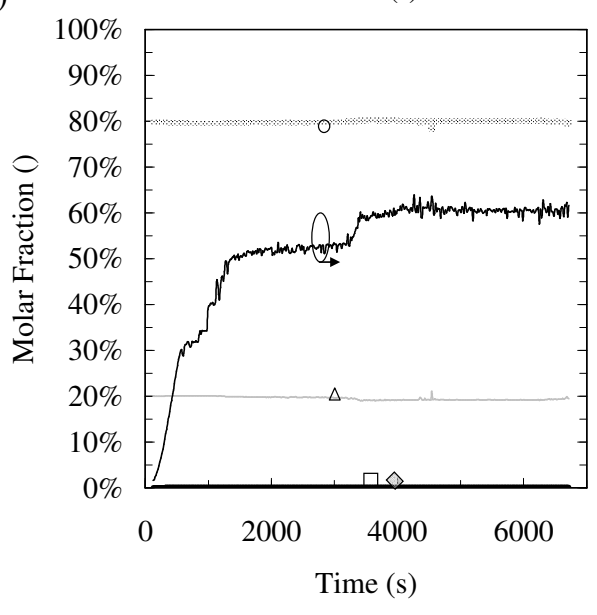

b)

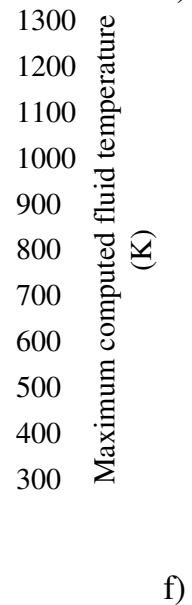



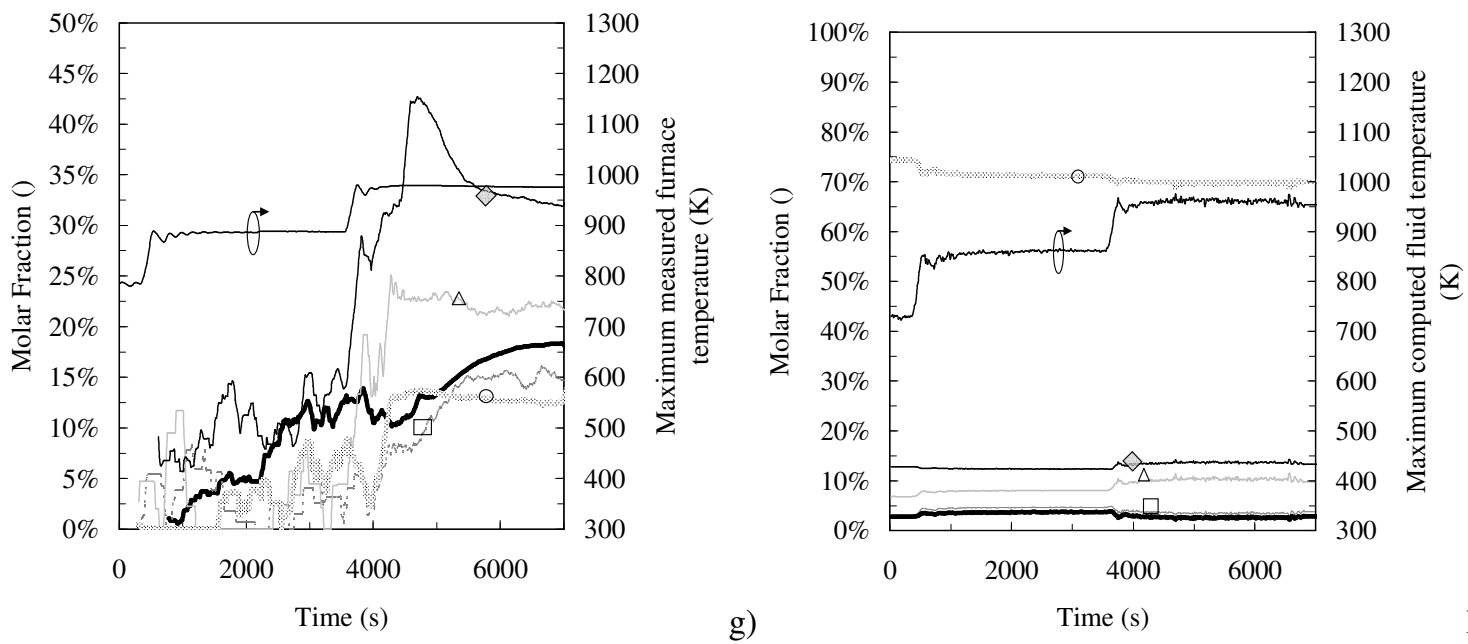

\begin{tabular}{|lll}
$-\diamond \mathrm{CH} 4$ & $\mathrm{O} 2 \mathrm{H} 4$ & $\triangle \mathrm{C} 2 \mathrm{H} 6$ \\
$-\square-\mathrm{C} 3 \mathrm{H} 6$ & $-\mathrm{C} 3 \mathrm{H} 8$ & - Temperature
\end{tabular}

Figure 8. Relative gaseous pyrolysis product mole fractions formed during heptane (a and $b: 1^{\text {st }}$ test and $\mathrm{c}$ and d: $2^{\text {nd }}$ test), decane (e and $\mathrm{f}$ ) and kerosene ( $\mathrm{g}$ and $\mathrm{h}$ ) thermal decomposition estimated by FTIR measures (a, c, $e$ and $g$ ) and by RESPIRE (b, $d, f$ and $h$ ). 

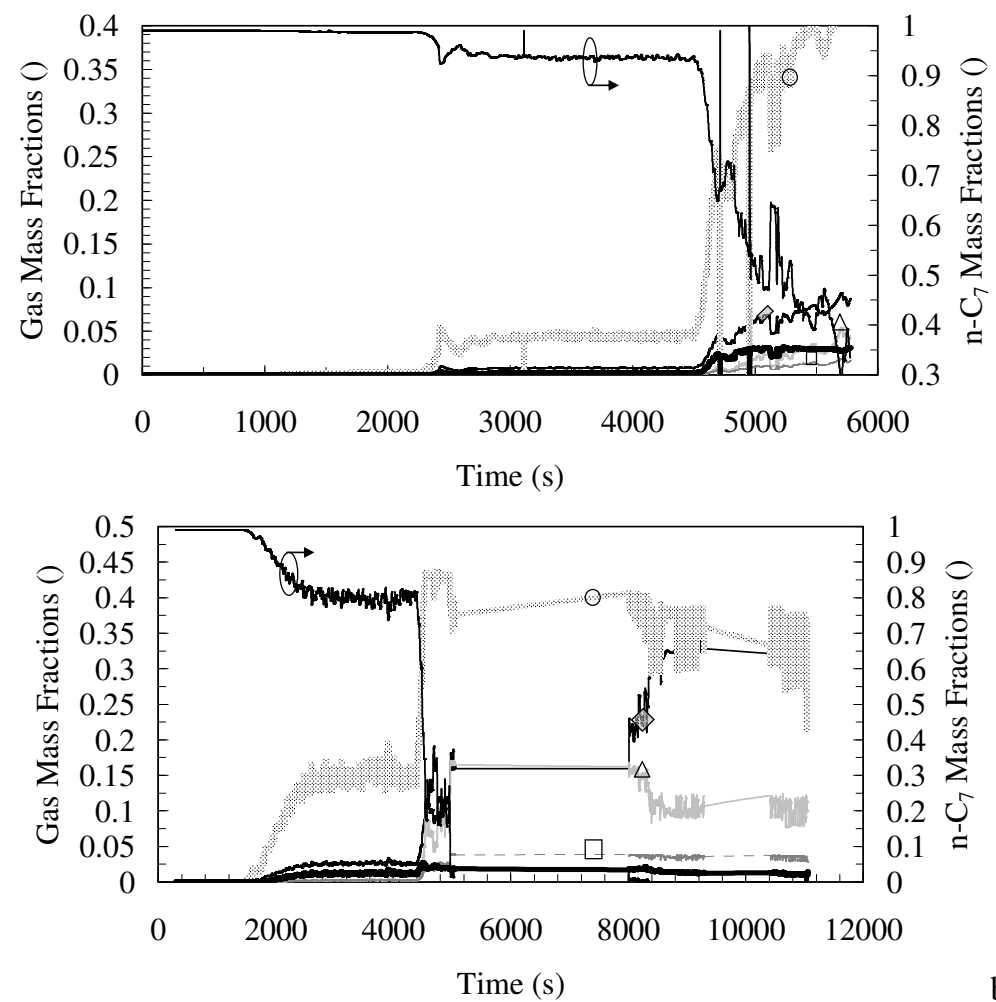

a)

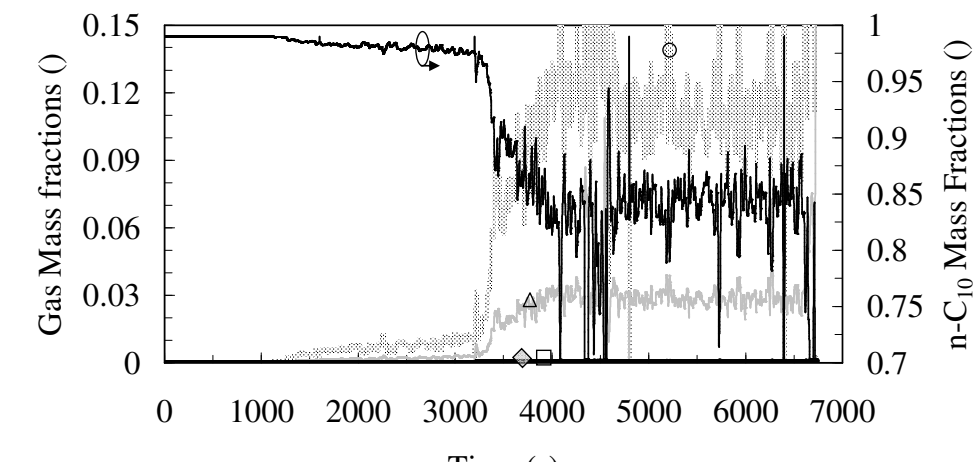

b)

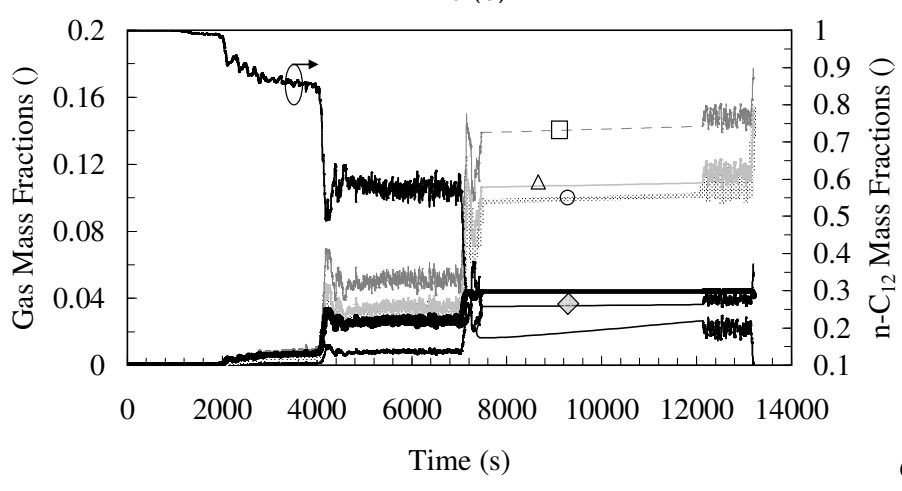

c)

d) 


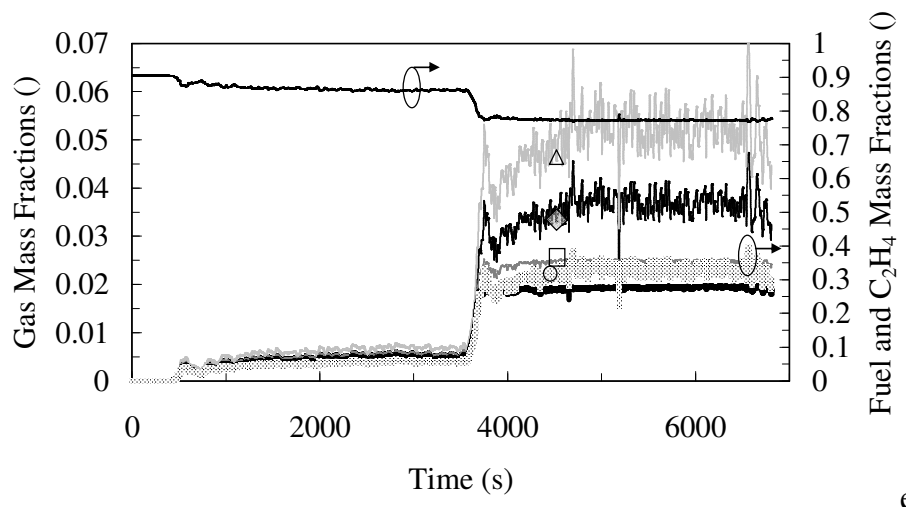

e)

\begin{tabular}{|c|c|}
\hline$\diamond-\mathrm{CH} 4$ & $\mathrm{O}$ C2H4 \\
\hline$-\boxminus-\mathrm{C} 3 \mathrm{H} 6$ & $-\mathrm{C} 3 \mathrm{H} 8$ \\
\hline
\end{tabular}

Figure 9. Absolute gaseous pyrolysis product mass fractions formed during heptane (a) $1^{\text {st }}$ test and (b) $2^{\text {nd }}$ test, decane (c), dodecane (d) and kerosene (e) thermal decomposition estimated by RESPIRE. 

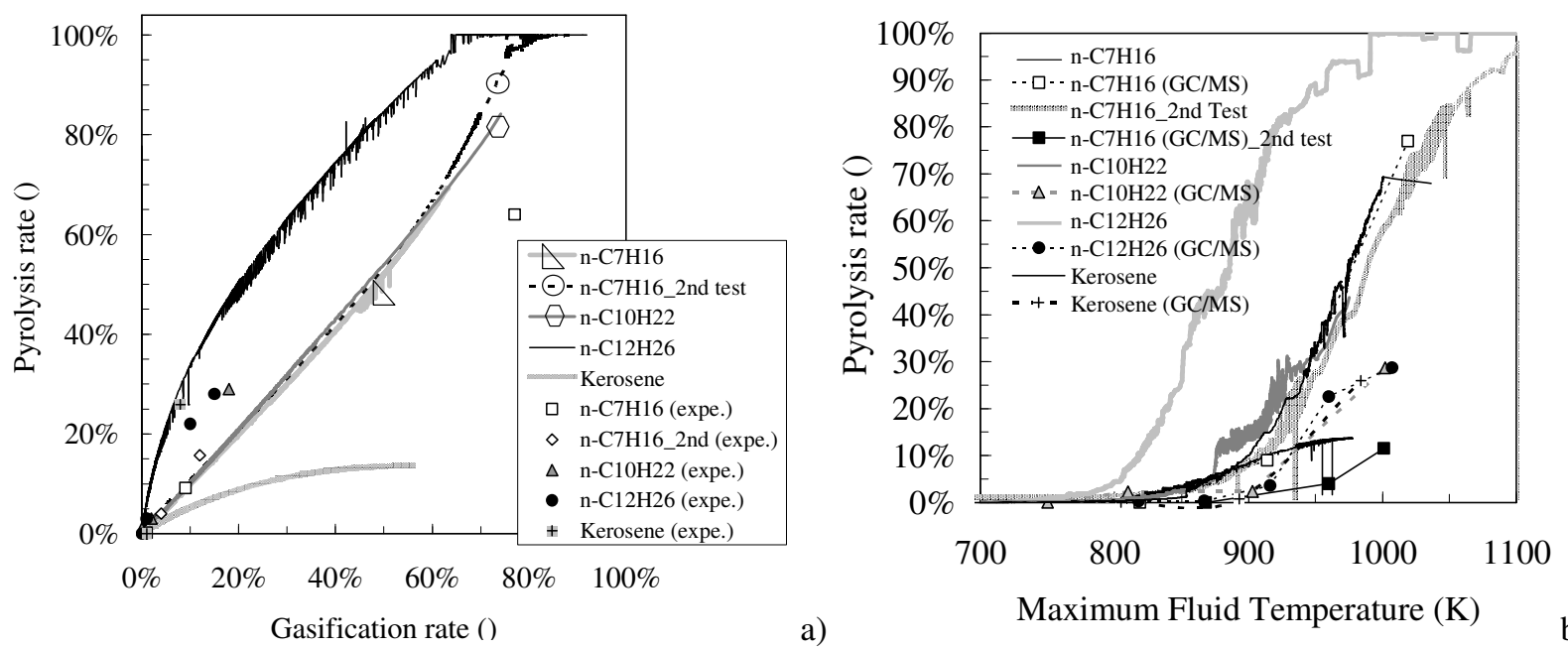

Figure 10. Estimation of pyrolysis products nature by comparison of pyrolysis and gasification rate of several fuels (a) and pyrolysis rate as a function of temperature (b) with comparison to experimental data. 


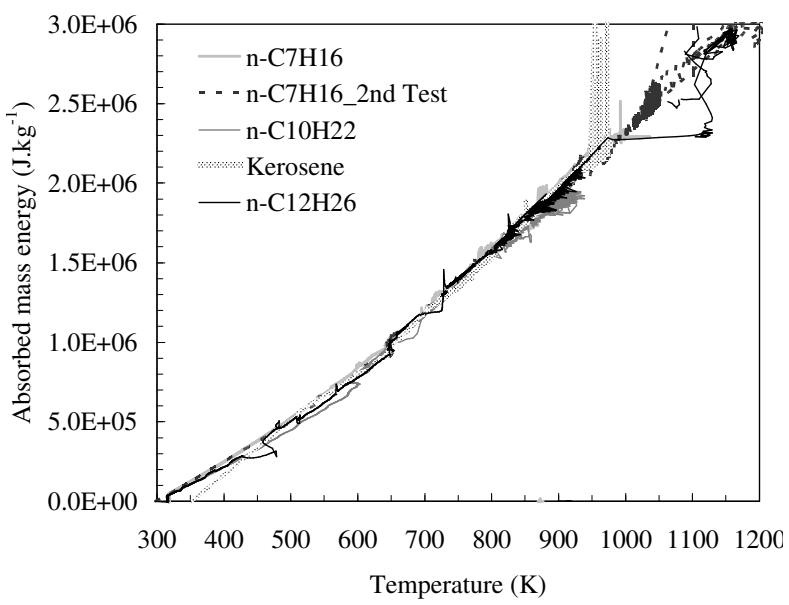

Figure 11. Endothermic effect of pyrolysis. 

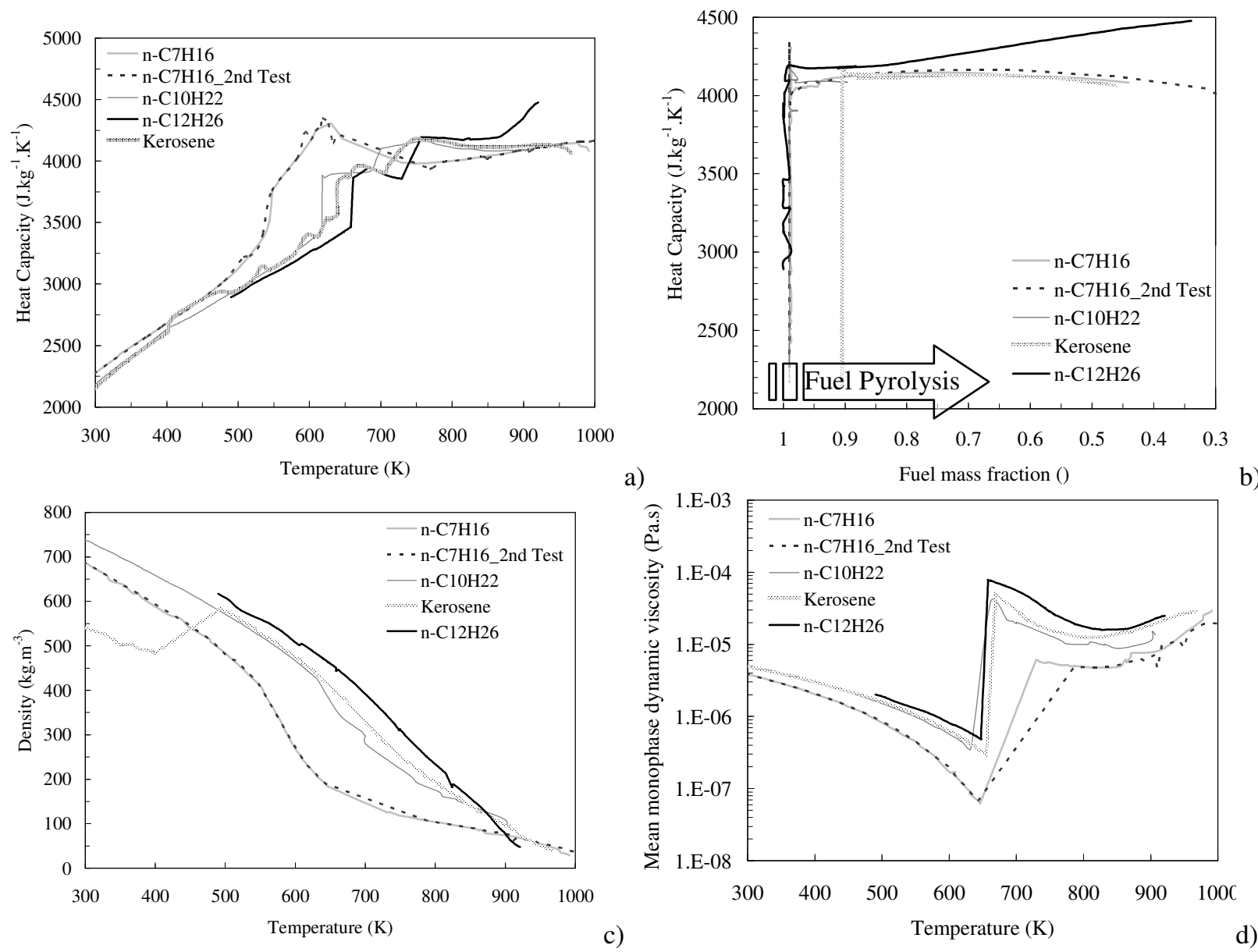

Figure 12. Heat capacity as a function of temperature (a) and of fuel mass fraction (b); density (c) and viscosity (d) of pyrolysis products for four different fuels at 60 bars. 


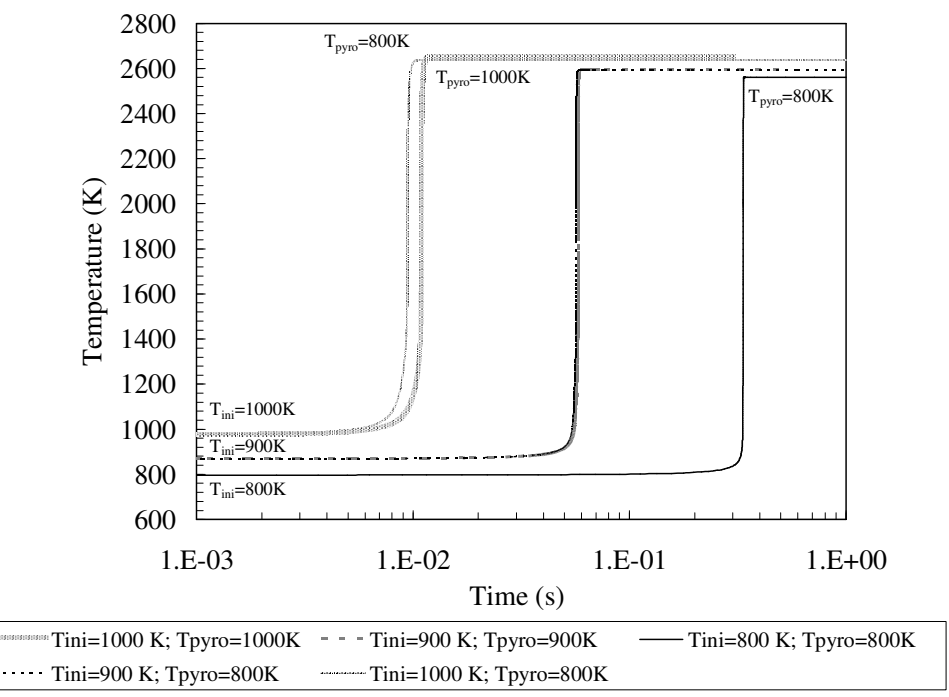

Figure 13. 0-D combustion of heptane pyrolysis products at different ignition temperature and for different compositions. 


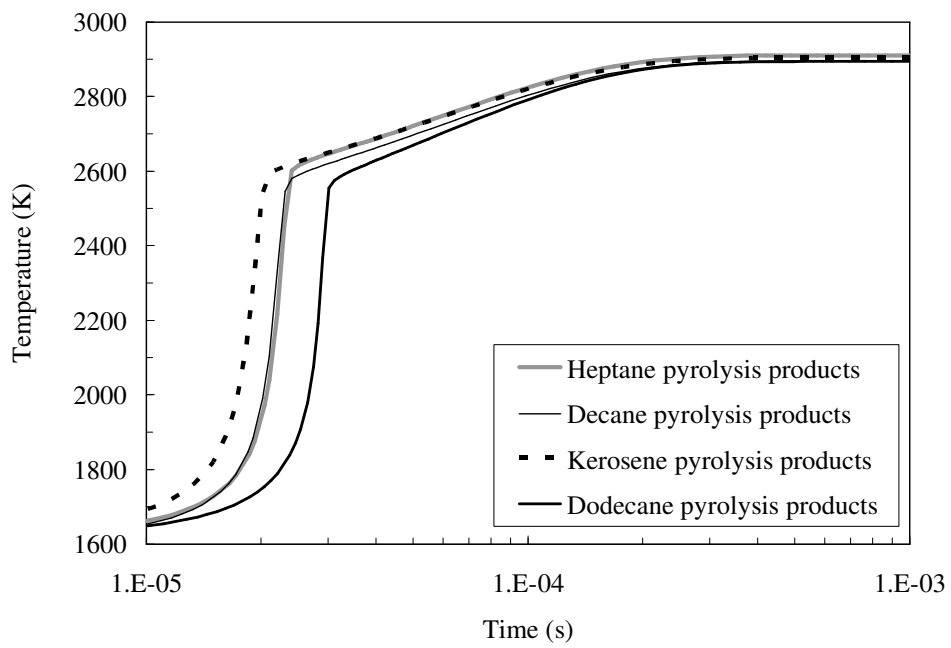

Figure 14. Flame temperature and ignition time of pyrolysis products of several fuels. 


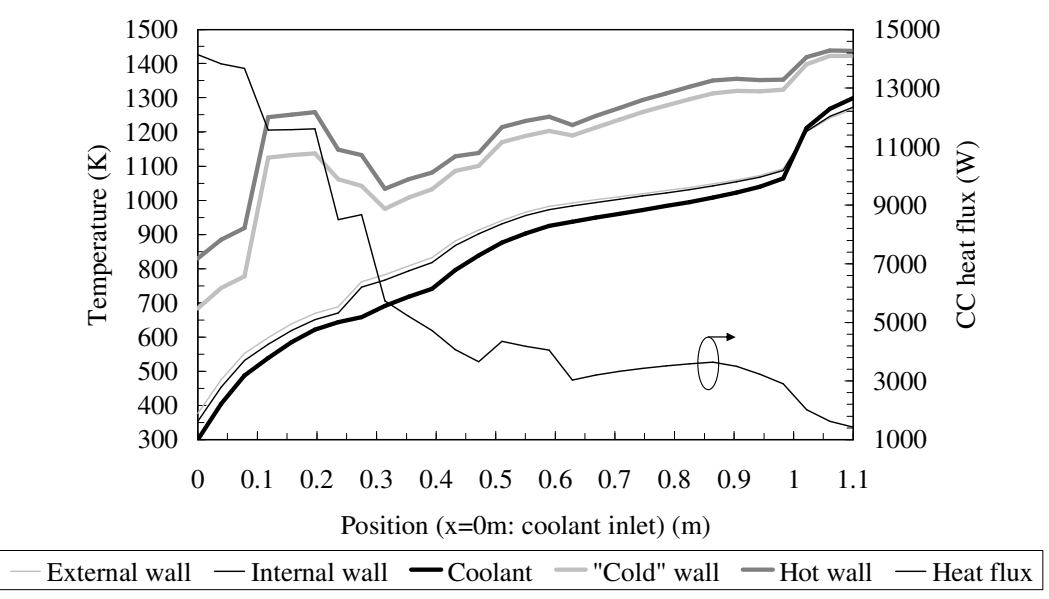

Figure 15. Temperature profiles of different parts in the cooling channel and applied $\mathrm{CC}$ heat flux. 

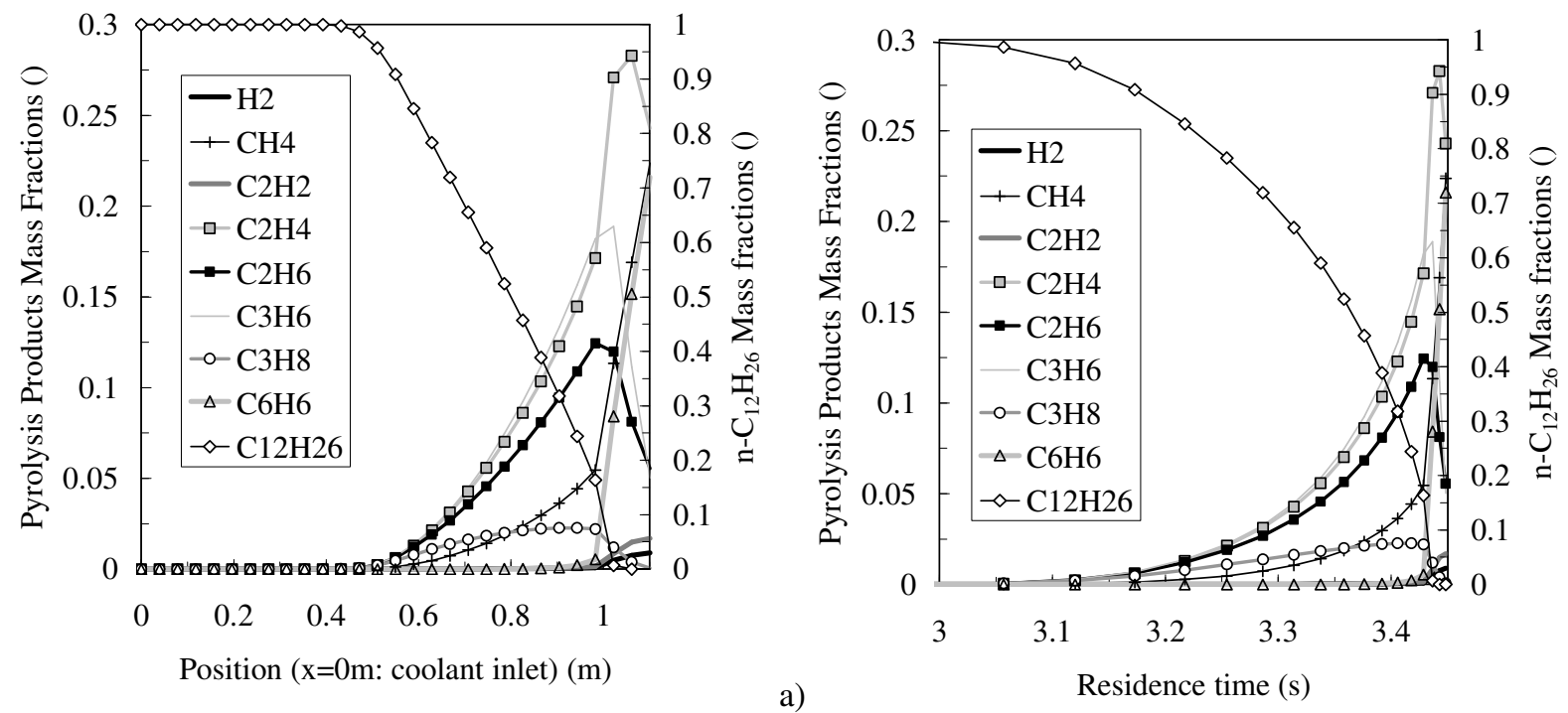

b)

Figure 16. Formation and consumption of main pyrolysis products inside the cooling channel (a) and as a function of residence time $(b)$. 


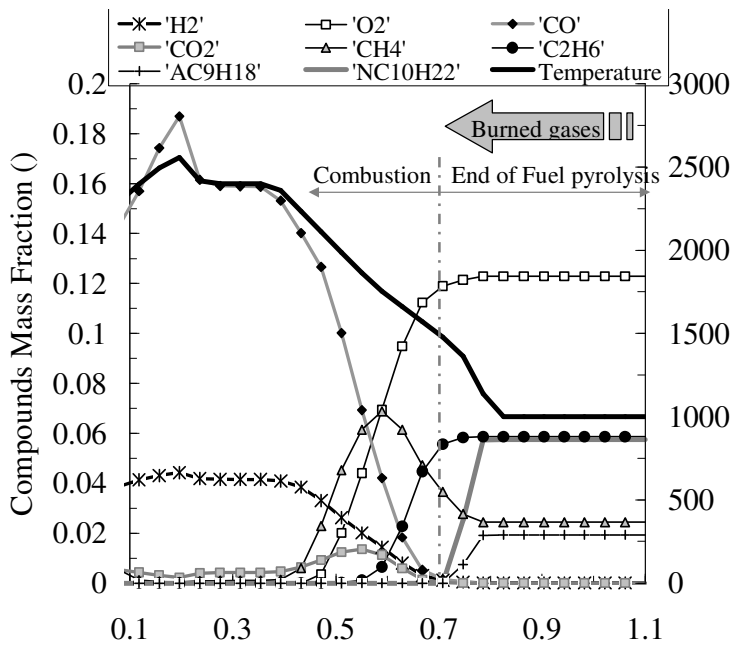

Position along the combustion chamber $(\mathrm{m})(\mathrm{x}=1.1 \mathrm{~m}$ : inlet $)$

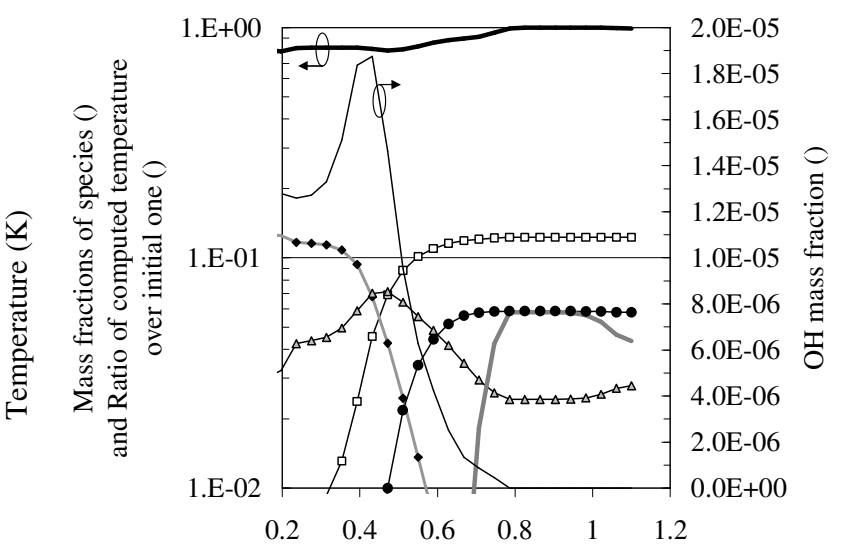

Position along the chamber $(\mathrm{m})(\mathrm{x}=1.1$ : inlet $)$

Figure 17. Stationary chemical composition profile in combustion chamber (air inlet at $1.1 \mathrm{~m}$ ) with fixed temperature (a) and with computed one due to combustion (b). 

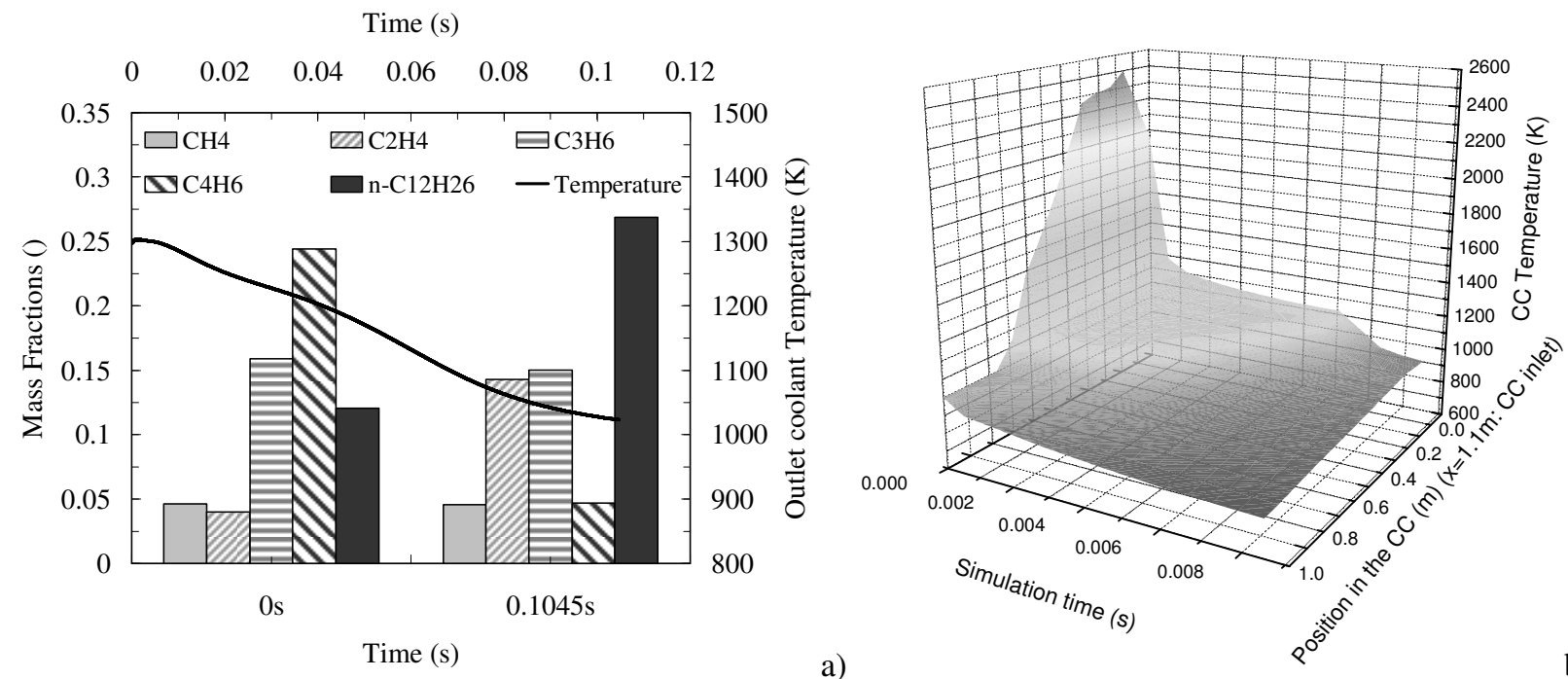

b)

Figure 18. Transient composition of pyrolysed coolant at channel outlet during temperature decrease due to extinction of the engine (a) and $\mathrm{CC}$ temperature decrease due to high auto-ignition delay of injected fuel (b). 